\title{
Molecular Typing and Phenotypic and Genotypic Evaluation of Antibiotic Resistance and Virulence Factors of the Methicillin-Resistant Staphylococcus Aureus Bacteria Isolated From Vegetable and Salad Samples
}

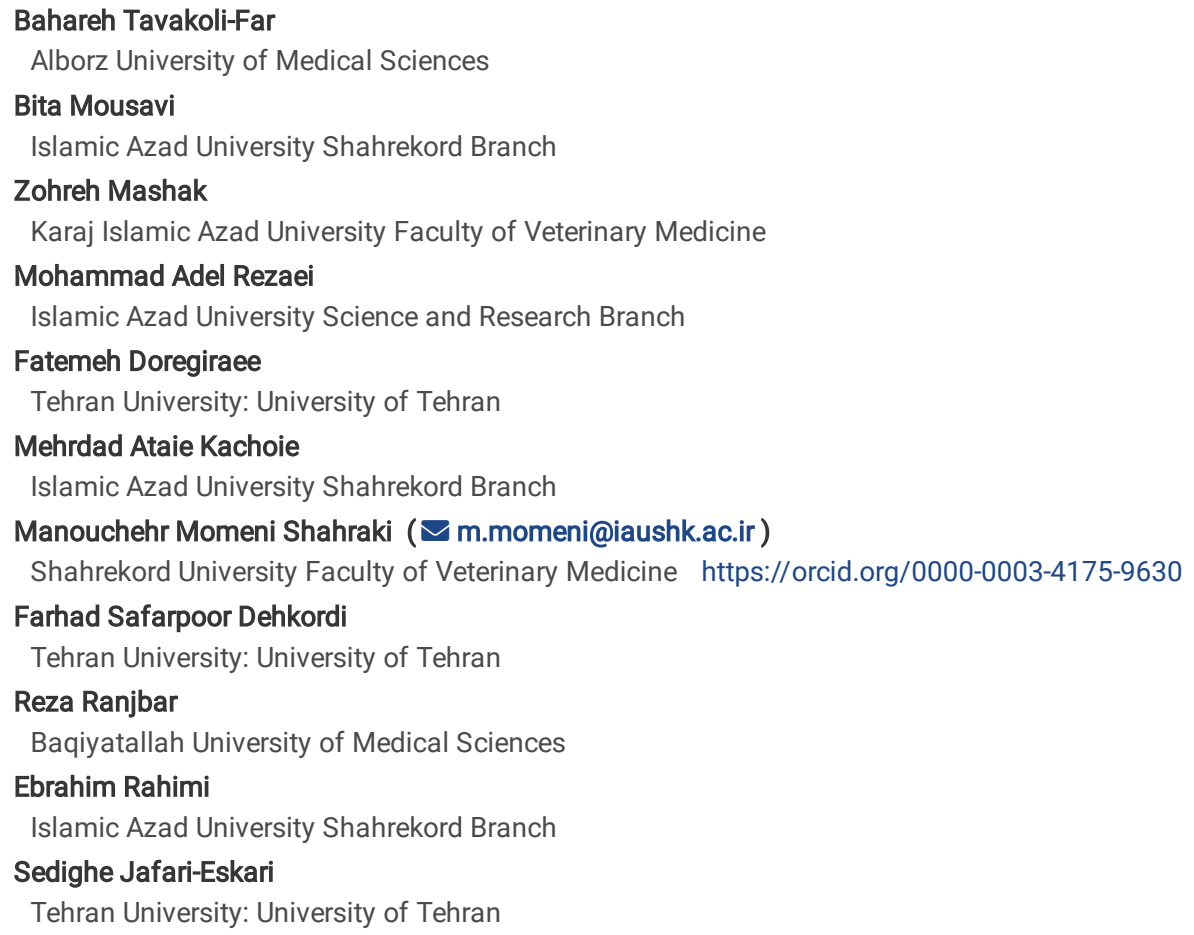

Research

Keywords: Methicillin-resistant Staphylococcus aureus, Virulence factors, Antibiotic resistance, RAPD-PCR, Vegetable, Salad

Posted Date: December 2nd, 2020

DOI: https://doi.org/10.21203/rs.3.rs-116662/v1

License: (1) This work is licensed under a Creative Commons Attribution 4.0 International License. Read Full License 


\section{Abstract}

Background

Methicillin-resistant Staphylococcus aureus is an important cause of foodborne diseases. The present research evaluated the antibiotic resistance properties, distribution of virulence factors, and molecular typing of MRSA bacteria isolated from vegetable and salad samples.

Methods

Three-hundred and fifty vegetable and salad samples were examined for the presence of $S$. aureus using the culture. MRSA bacteria were identified using cefoxitin and oxacillin disk diffusion. The phenotypic pattern of antibiotic resistance was assessed by disk diffusion.

Results

The PCR evaluated the distribution of antibiotic resistance and virulence genes. Forty-five out of 350 (12.85\%) vegetable and salad samples were positive for S. aureus. Twenty-six isolates out of $45(57.77 \%)$ S. aureus bacteria were determined as MRSA. MRSA bacteria harbored the uppermost prevalence of resistance against cefoxitin (100\%), ceftaroline (100\%), penicillin (100\%), tetracycline (88.46\%), gentamicin (80.76\%), trimethoprim-sulfamethoxazole (69.23\%), and erythromycin (69.23\%). The prevalence of MRSA bacteria resistance recovered from vegetable and salad samples against more than seven antibiotic agents was $12.50 \%$ and $27.77 \%$, respectively. BlaCTX-M (100\%), blaZ (100\%), aacA-D (61.53\%), tetK (57.69\%), dfrA1 (46.15\%), and vanA (42.30\%) were the most commonly detected antibiotic resistance genes. PVL (57.69\%), coa (53.84\%), and $h / a(38.46 \%)$ were the most commonly detected virulence factors amongst the MRSA bacteria.

Conclusion

MRSA isolates had a similarity lower than $80 \%$, categorized in the same group. The presence of one or more virulence factors and antibiotic resistance genes amongst the resistant-MRSA bacteria signifies an important threat rendering the consumption of contaminated vegetables and salads.

\section{Background}

As healthy foods, vegetables, and salad are a bundle of nutrient components with high beneficial effects for human health [1]. They are full of vitamins and some kinds of minerals essential for the routine function of the body. Nevertheless, close contact of vegetables with contaminated water, soil, human and animal fertilizers, and human involvement in salad processing caused the potential risk of microbial contamination [2,3]. Consumption of contaminated vegetables and salad may cause severe foodborne diseases with a high economic burden $[4,5]$

Staphylococcus aureus (S. aureus) is a Gram-positive, catalase-positive, and cocci-shaped bacterium originate from the upper respiratory tract and skin [6-9] It is mostly responsible for severe nosocomial and community-acquired infections, foodborne diseases, and food poisoning [6-9]. The occurrence of diverse kinds of gastrointestinal diseases with abdominal cramps, nausea, vomiting, weakness, diarrhea, and toxic shock syndrome (TSS) is attributed to $S$. aureus [6-9]. S. aureus strains have been isolated from numerous kinds of food samples, particularly ready to eat vegetables and salads [10, 11].

The emergence of antibiotic-resistant strains of this bacterium is one of the main issues in treating foodborne diseases [12]. At this time, methicillin-resistant S. aureus (MRSA) has converted a considerate problem in hospitals and the community [13]. MRSA bacteria are responsible for more severe clinical diseases with higher morbidity and mortality rates [14]. Furthermore, the MRSA strains mainly resist numerous kinds of antibiotics, particularly cephalosporins and penicillins $[13,14]$. In keeping with this, MRSA bacteria harbored considerable resistance toward other antibiotics classes [13, 14]. The presence of antibiotic resistance encoding genes is a significant way of antibiotic resistance in bacteria [15]. The genes that encode resistance toward cephems (blaCTX-M), glycopeptides (vanA), penicillins (blaZ), aminoglycosides (aacA-D), streptogramins (vatA), tetracyclines (tetK and tetM), ansamycins ( $r p o B)$, folate pathway inhibitors (dfrA1), macrolides (ermA and $m s r A$ ), ansamycins $(r p o B)$, and fluoroquinolones ( $g y r A$ and grlA) groups of antibiotics had considerable distribution amongst the MRSA bacteria [15].

The presence of virulence factors is another significant issue regarding MRSA complications. Some virulence factors are mostly accompanied by the pathogenesis of MRSA infections [16, 17]. Coagulase (coa), toxic shock syndrome toxin-1 (TSST-1), exfoliative toxin A (eta), hemolysin ( $h / a)$, and fibronectin binding protein $(f n b A)$ are the most significant virulence factors of the MRSA bacteria associated with the occurrence of nosocomial and community infections $[16,17]$. Another significant virulence factor of the MRSA bacteria with leukocidal and cytotoxic activities is Panton-Valentine leukocidin (PVL), with a high portion in the pathogenicity of related infections [18].

Molecular genotyping is one of the best methods to originated the genetic association amid bacteria recovered from numerous sources. Randomly Amplified Polymorphic DNA (RAPD)-PCR, a simple, accurate, and rapid method, has been expansively used for the epidemiological examination to assess the genetic variation and establish strain-specific fingerprints [19]. In epidemiological surveys, it is essential to assess the genetic variations amid numerous samples and pathogenic agents.

The exact role of virulent and antibiotic-resistant-MRSA on the occurrence of foodborne diseases has not been precisely identified. Thus, the present examination was performed to evaluate the prevalence, molecular typing, phenotypic and genotypic properties the antibiotic resistance, and distribution of virulence factors amongst the MRSA bacteria isolated from vegetable and salad samples, which were packed traditionally.

\section{Methods}




\section{Samples}

From September 2019 to January 2020, a total of 350 raw vegetable $(n=180)$ and salad $(n=170)$ samples were randomly collected from retail centers of the Chaharmahal Va Bakhtiari province, Iran. Both vegetable and salad samples were packed traditionally. Salad samples were collected from restaurants. A total of $50 \mathrm{~g}$ samples were collected from each vegetable and salad using sterile laboratory tubes. Samples were proximately transferred to the laboratory using cool bags.

\section{Isolation and identification of S. aureus}

Twenty-five grams of each collected vegetable and salad samples were blended with $225 \mathrm{~mL}$ of buffered peptone water (Merck, Germany). At that moment, solutions were homogenized using Stomacher (Interscience, Saint-Nom, France). At that time, five milliliters of the achieved solution were transferred into $50 \mathrm{~mL}$ Trypticase Soy Broth (TSB, Merck, Germany) supplemented with $10 \% \mathrm{NaCl}$ and $1 \%$ sodium pyruvate incubated for $18 \mathrm{~h}$ at $35^{\circ} \mathrm{C}$. At that moment, a loopful of the culture was transferred into Baird-Parker agar supplemented with egg yolk tellurite emulsion (Merck, Germany) and incubated at $37{ }^{\circ} \mathrm{C}$ for $24 \mathrm{~h}$. Black shiny colonies enclosed with significant zones were identified using biochemical tests including Gram staining, oxidase test, catalase activity, resistance to bacitracin (0.04 U), coagulated test (rabbit plasma), urease activity, glucose O/F test, voges-proskaver (Merck, Germany) test, nitrate reduction, phosphatase, deoxyribonuclease (DNase, Merck, Germany) test, mannitol fermentation, hemolysis activity on blood agar (Merck, Germany) and carbohydrate (xylose, sucrose, trehalose and maltose, fructose, lactose, mannose) fermentation tests [20].

\section{MRSA identification}

Antibiotic susceptibility tests were applied for this purpose. Susceptibility of $S$. aureus isolates was tested against cefoxitin ( $30 \mu \mathrm{g})$ and oxacillin ( $1 \mu \mathrm{g})$ antibiotic disks. The experiment was completed by the instructions of the Clinical and Laboratory Standards Institute (CLSI) [21]. S. aureus isolates simultaneously resist against both cefoxitin and oxacillin antibiotic disks were considered MRSA strains. Confirmation of MRSA isolates was also performed using the PCR-based detection mecA gene [20].

\section{Phenotypic evaluation of antibiotic resistance of MRSA strains}

The phenotypic pattern of antibiotic resistance of MRSA bacteria isolated from vegetable and salad samples was assessed by the disk diffusion method using the Mueller-Hinton agar (Merck, Germany) medium. Guidelines of the Clinical and Laboratory Standards Institute (CLSI) were used for this goal [22] Diverse kinds of antibiotic groups including cephems (cefoxitin $(30 \mu \mathrm{g} / \mathrm{disk})$ and ceftaroline $(30 \mu \mathrm{g} / \mathrm{disk})$ ), penicillins (penicillin (10 units/disk)), aminoglycosides (gentamicin $(15 \mu \mathrm{g} /$ disk)), glycopeptides (vancomycin $(5 \mu \mathrm{g} /$ disk)), macrolides (azithromycin $(15 \mu \mathrm{g} /$ disk) and erythromycin $(15 \mu \mathrm{g} /$ disk)), fluoroquinolones (ciprofloxacin $(5 \mu \mathrm{g} / \mathrm{disk})$ and levofloxacin $(5 \mu \mathrm{g} / \mathrm{disk}))$, tetracyclines (tetracycline $(30 \mu \mathrm{g} / \mathrm{disk})$ and doxycycline $(30 \mu \mathrm{g} / \mathrm{disk}))$, nitrofurantoins (nitrofurantoin $(300 \mu \mathrm{g} /$ disk)), folate pathway antagonists (trimethoprim-sulfamethoxazole $(1.25 / 23.75 \mu \mathrm{g} /$ disk)), ansamycins (rifampin (5 $\mu \mathrm{g} /$ disk)), and streptogramins (quinupristin-dalfopristin ( $15 \mu \mathrm{g} /$ disk)) (Oxoid, UK) were used. Media contained the MRSA isolates, and disks were incubated $37^{\circ} \mathrm{C}$ for $24 \mathrm{~h}$, and the diameter of the growth inhibition zone was measured and interpreted by the protocols of the CLSI [22]. MRSA ATCC 43300 was used as control.

\section{Genotypic evaluation of antibiotic resistance and distribution of virulence factors of the MRSA strains}

Assessment of genotypic pattern of antibiotic resistance (distribution of antibiotic resistance encoding genes) and virulence factors of the MRSA isolates was performed by the Polymerase Chain Reaction (PCR). The method was designed to detect at least one antibiotic resistance encoding gene from each antibiotic group. Additionally, the presence of some of the most important virulence factors responsible for the pathogenesis of staphylococcal infections were examined. First of all, DNA was extracted from MRSA colonies. MRSA isolates were sub-cultured on TSB media (Merck, Germany) and incubated for $48 \mathrm{~h}$ at $37^{\circ} \mathrm{C}$. Genomic DNA was extracted from MRSA colonies using the DNA extraction kit (Thermo Fisher Scientific, St. Leon-Rot, Germany). Guidelines of the producing company were performed for this purpose. Purity (A260/A280) of extracted DNA was examined by the NanoDrop device (NanoDrop, Thermo Scientific, Waltham, MA, USA). The quality of extracted DNA was examined using electrophoresis on $2 \%$ agarose gel. Table 1 displays the PCR circumstances used for this genetic evaluation [9, 23-29]. PCR was performed using the programmable DNA thermo-cycler (Eppendorf Mastercycler 5330, Germany). Amplified products were analyzed by electrophoresis $(120 \mathrm{~V} / 208 \mathrm{~mA})$ in $2.5 \%$ agarose gel. The gel was stained with $0.1 \%$ ethidium bromide $(0.4 \mu \mathrm{g} / \mathrm{ml}$, (Thermo Fisher Scientific, St. Leon-Rot, Germany). The UVI doc gel documentation systems (Grade GB004, Jencons PLC, London, UK) was used to assess the results of the PCR. 
Table 1

PCR circumstances used to detect antibiotic resistance encoding genes and virulence factors amongst the MRSA isolates of vegetable and salad samples [9,

\begin{tabular}{|c|c|c|c|c|c|}
\hline $\begin{array}{l}\text { Target } \\
\text { gene }\end{array}$ & Encoding antibiotic & Primer sequence (5'-3') & $\begin{array}{l}\text { PCR } \\
\text { product } \\
\text { (bp) }\end{array}$ & $\begin{array}{l}\text { PCR } \\
\text { programs }\end{array}$ & PCR volume $(50 \mu \mathrm{L})$ \\
\hline \multirow[t]{2}{*}{ aacA-D } & \multirow[t]{2}{*}{ Aminoglycosides } & F: TAATCCAAGAGCAATAAGGGC & \multirow[t]{2}{*}{227} & 1 cycle: & $5 \mu \mathrm{L}$ PCR buffer $10 \mathrm{X}$ \\
\hline & & R: GCCACACTATCATAACCACTA & & $94^{\mathrm{OC}}$ & $1.5 \mathrm{mM} \mathrm{MgCl}_{2}$ \\
\hline \multirow[t]{2}{*}{ ermA } & \multirow[t]{2}{*}{ Macrolides } & F: AAGCGGTAAACCCCTCTGA & \multirow[t]{2}{*}{190} & & $200 \mu \mathrm{M}$ dNTP (Thermo Fisher Scientific, St. \\
\hline & & R: TTCGCAAATCCCTTCTCAAC & & & \\
\hline \multirow[t]{4}{*}{ tetK } & \multirow[t]{4}{*}{ Tetracyclines } & F: GTAGCGACAATAGGTAATAGT & \multirow[t]{3}{*}{360} & $-60 s$ & 1.25 U Taq DNA polymerase (Thermo Fisher \\
\hline & & & & $55^{0 \mathrm{C}}$ & $\begin{array}{l}\text { Scientific, St. Leon-Rot, Germany) } \\
2.5 \mu \mathrm{L} \text { DNA template }\end{array}$ \\
\hline & & & & $\frac{72^{0 \mathrm{C}}}{-60 \mathrm{~s}}$ & \\
\hline & & R: GTAGTGACAATAAACCTCCTA & & 1 cycle: & \\
\hline \multirow[t]{2}{*}{ grlA } & \multirow[t]{2}{*}{ Fluoroquinolones } & F: ACTTGAAGATGTTTTAGGTGAT & \multirow[t]{2}{*}{618} & $72^{0 \mathrm{C}} \overline{\mathrm{min}}$ & \\
\hline & & R: TTAGGAAATCTTGATGGCAA & & & \\
\hline \multirow[t]{5}{*}{ tetM } & \multirow[t]{5}{*}{ Tetracyclines } & F: AGTGGAGCGATTACAGAA & \multirow[t]{5}{*}{158} & 1 cycle: & $5 \mu \mathrm{L}$ PCR buffer $10 \mathrm{X}$ \\
\hline & & R: CATATGTCCTGGCGTGTCTA & & $94^{0 \mathrm{C}}$ & $2 \mathrm{mM} \mathrm{MgCl} 2$ \\
\hline & & & & 34 cycles. & $200 \mu \mathrm{M}$ dNTP \\
\hline & & & & & $0.5 \mu \mathrm{M}$ of each primers $\mathrm{F} \& \mathrm{R}$ \\
\hline & & & & $-50 \mathrm{~s}$ & 1.5 U Taq DNA polymerase \\
\hline \multirow[t]{4}{*}{ gyrA } & \multirow[t]{4}{*}{ Fluoroquinolones } & F: AGTACATCGTCGTATACTATATGG & \multirow[t]{4}{*}{280} & $55^{0 \mathrm{C}}-70_{\mathrm{s}}$ & 5 $\mu \mathrm{L}$ DNA template \\
\hline & & R: ATCACGTAACAGTTCAAGTGTG & & $72^{0 \mathrm{c}}$ & \\
\hline & & & & 1 cycle: & \\
\hline & & & & $\begin{array}{l}72^{\circ \mathrm{C}} \\
-8 \mathrm{~min}\end{array}$ & \\
\hline \multirow[t]{2}{*}{ msrA } & \multirow[t]{2}{*}{ Macrolides } & F: GGCACAATAAGAGTGTTTAAAGG & \multirow[t]{2}{*}{940} & 1 cycle: & $5 \mu \mathrm{L}$ PCR buffer $10 \mathrm{X}$ \\
\hline & & R: AAGTTATATCATGAATAGATTGTCCTGTT & & $94^{\mathrm{OC}}$ & $2 \mathrm{mM} \mathrm{MgCl} 2$ \\
\hline \multirow[t]{7}{*}{ dfrA1 } & \multirow{2}{*}{$\begin{array}{l}\text { Folate pathway } \\
\text { antagonists }\end{array}$} & F: CTCACGATAAACAAAGAGTCA & \multirow[t]{2}{*}{201} & \multirow{2}{*}{34 cycles: } & $150 \mu \mathrm{M}$ dNTP \\
\hline & & R: CAATCATTGCTTCGTATAACG & & & $0.75 \mu \mathrm{M}$ of each primers $\mathrm{F} \& \mathrm{R}$ \\
\hline & & & & $\frac{95^{0 \mathrm{C}}}{-60 \mathrm{~s}}$ & 1.5 U Taq DNA polymerase \\
\hline & & & & $50^{0 \mathrm{C}}$ & $3 \mu \mathrm{L}$ DNA template \\
\hline & & & & $\frac{72^{0 C}}{-70 \mathrm{~s}}$ & \\
\hline & & & & 1 cycle: & \\
\hline & & & & $\begin{array}{l}72^{\circ \mathrm{C}} \\
-8 \mathrm{~min}\end{array}$ & \\
\hline
\end{tabular}

\begin{tabular}{|c|c|c|c|c|c|}
\hline \multirow[t]{2}{*}{ rров } & \multirow[t]{2}{*}{ Ansamycins } & F: ACCGTCGTTTACGTTCTGTA & \multirow[t]{2}{*}{460} & 1 cycle: & $5 \mu \mathrm{L}$ PCR buffer $10 \mathrm{X}$ \\
\hline & & R: TCAGTGATAGCATGTGTATC & & $\begin{array}{l}\frac{94}{0 \mathrm{C}} \mathrm{min} . \\
40 \text { cycles: }\end{array}$ & $\begin{array}{l}2 \mathrm{mM} \mathrm{MgCl} \\
150 \mu \mathrm{M} \text { dNTP } \\
0.75 \mu \mathrm{M} \text { of each primers } \mathrm{F} \& \mathrm{R}\end{array}$ \\
\hline \multicolumn{4}{|c|}{${ }^{\mathrm{a}} \mathrm{R}$ is $\mathrm{A}$ or $\mathrm{G}$; $\mathrm{Y}$ is $\mathrm{C}$ or $\mathrm{T}$; $\mathrm{S}$ is $\mathrm{G}$ or $\mathrm{C}$. } & $\begin{array}{l}94^{\mathrm{OC}} \\
-40 \mathrm{~s}\end{array}$ & 1.5 U Taq DNA polymerase \\
\hline
\end{tabular}




\begin{tabular}{|c|c|c|c|c|c|}
\hline $\begin{array}{l}\text { Target } \\
\text { gene }\end{array}$ & Encoding antibiotic & Primer sequence $\left(5^{\prime}-3^{\prime}\right)$ & $\begin{array}{l}\text { PCR } \\
\text { product } \\
\text { (bp) }\end{array}$ & $\begin{array}{l}\text { PCR } \\
\text { programs }\end{array}$ & Ṕdk Dolume (50 atê) \\
\hline & & & & $\begin{array}{l}\frac{45.5 \mathrm{oc}}{-40 \mathrm{~s}} \\
720 \mathrm{C} \\
-90 \mathrm{~s} \\
1 \text { cycle: } \\
720 \mathrm{c} \\
-8 \mathrm{~min}\end{array}$ & \\
\hline blaz & Penicillins & $\begin{array}{l}\text { F: TGAACCGTATGTTAGTGC } \\
\text { R: GTCGTGTTAGCGTTGATA }\end{array}$ & 681 & 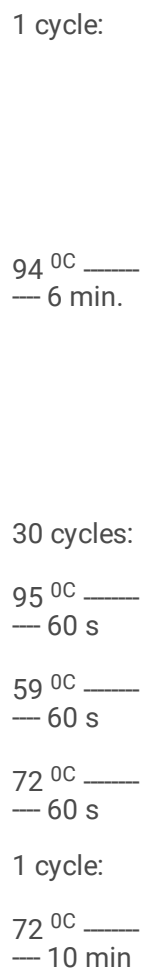 & $\begin{array}{l}5 \mu \mathrm{L} \text { PCR buffer } 10 \mathrm{X} \\
2 \mathrm{mM} \mathrm{MgCl}_{2} \\
150 \mu \mathrm{M} \text { dNTP } \\
0.75 \mu \mathrm{M} \text { of each primers } \mathrm{F} \& \mathrm{R} \\
1.5 \mathrm{U} \text { Taq DNA polymerase } \\
3 \mu \mathrm{L} \text { DNA template }\end{array}$ \\
\hline
\end{tabular}

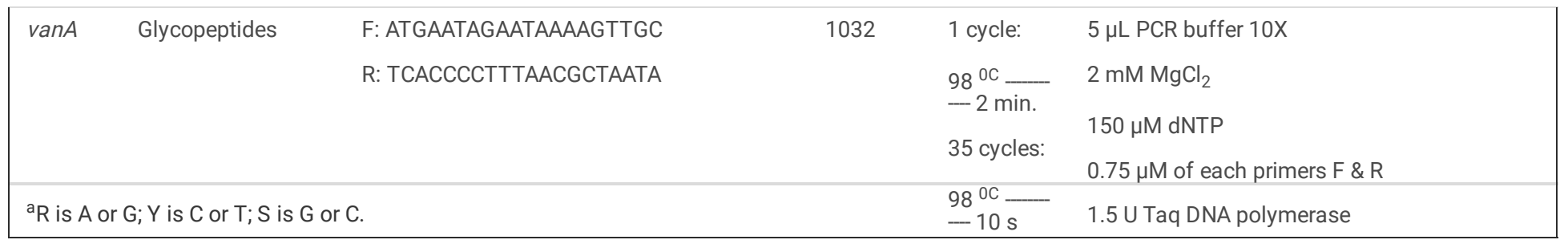




\begin{tabular}{|c|c|c|c|c|c|}
\hline \multirow[t]{4}{*}{$\begin{array}{l}\text { Target } \\
\text { gene }\end{array}$} & Encoding antibiotic & Primer sequence $\left(5^{\prime}-3^{\prime}\right)$ & $\begin{array}{l}\text { PCR } \\
\text { product } \\
\text { (bp) }\end{array}$ & $\begin{array}{l}\text { PCB } \\
\text { programs } \\
\text { progrs }\end{array}$ & 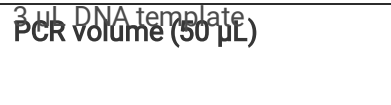 \\
\hline & & & & $\begin{array}{l}72^{0 \mathrm{C}} \\
-90 \mathrm{~s}\end{array}$ & \\
\hline & & & & 1 cycle: & \\
\hline & & & & $\frac{72^{\circ \mathrm{C}}}{-10_{\mathrm{min}}}$ & \\
\hline \multirow[t]{9}{*}{ vatA } & Streptogramins & F: TGGTCCCGGAACAACATTTAT & 268 & 1 cycle: & $5 \mu \mathrm{L}$ PCR buffer $10 \mathrm{X}$ \\
\hline & & R: TCCACCGACAATAGAATAGGG & & $94^{0 \mathrm{C}}$ & $2 \mathrm{mM} \mathrm{Mgcl}_{2}$ \\
\hline & & & & 34 cycle: & $200 \mu \mathrm{M}$ dNTP \\
\hline & & & & $95^{\circ} \mathrm{C}$ & $0.5 \mu \mathrm{M}$ of each primers \\
\hline & & & & $-50 s$ & 1.5 U Taq DNA polymerase \\
\hline & & & & $55^{\circ \mathrm{C}}$ & \\
\hline & & & & $\frac{72}{0 \mathrm{CC}}$ & \\
\hline & & & & 1 cycle: & $5 \mu \mathrm{L}$ DNA template \\
\hline & & & & $\begin{array}{l}72^{\circ \mathrm{C}} \\
-8 \mathrm{~min}\end{array}$ & \\
\hline \multirow{8}{*}{$\begin{array}{l}\text { blactX- } \\
M^{p}\end{array}$} & Cephems & F: ATGTGCAGYACCAGTAARGT & 593 & 1 cycle: & $5 \mu \mathrm{L}$ PCR buffer $10 \mathrm{X}$ \\
\hline & & R: TGGGTRAARTARGTSACCAGA & & $94^{0 \mathrm{C}}$ & \\
\hline & & & & 35 cycles: & $150 \mu \mathrm{M}$ dNIP \\
\hline & & & & $94{ }^{0 \mathrm{C}}$ & $1.5 \mathrm{U}$ Tag DNA polymerase \\
\hline & & & & $500 \mathrm{c}$ & \\
\hline & & & & $\frac{72}{-60 \mathrm{c}}$ & \\
\hline & & & & 1 cycle: & $3 \mu \mathrm{L} \mathrm{DNA}$ template \\
\hline & & & & $\begin{array}{l}72^{0 \mathrm{C}} \\
-5 \mathrm{~min}\end{array}$ & \\
\hline
\end{tabular}

\begin{tabular}{|c|c|c|c|c|c|}
\hline \multirow[t]{4}{*}{ coa } & \multirow[t]{4}{*}{ Coagulase } & F: CGAGACCAAGATTCAACAAG & \multirow[t]{4}{*}{970} & 1 cycle: & $5 \mu \mathrm{L}$ PCR buffer $10 \mathrm{X}$ \\
\hline & & \multirow[t]{3}{*}{ R: AAAGAAAACCACTCACATCA } & & $95^{\circ \mathrm{C}}$ & \\
\hline & & & & 30 cyce. & $200 \mu \mathrm{M}$ dNTP \\
\hline & & & & & $0.5 \mu \mathrm{M}$ of each primers $\mathrm{F} \& \mathrm{R}$ \\
\hline \multicolumn{4}{|c|}{ a $R$ is $A$ or $G$; $Y$ is $C$ or $T$; $S$ is $G$ or $C$. } & $\begin{array}{l}95^{\circ \mathrm{CC}} \\
-30 \mathrm{~s}\end{array}$ & 1.5 U Taq DNA polymerase \\
\hline
\end{tabular}




\begin{tabular}{|c|c|c|c|c|c|}
\hline $\begin{array}{l}\text { Target } \\
\text { gene }\end{array}$ & Encoding antibiotic & Primer sequence (5'-3') & $\begin{array}{l}\text { PCR } \\
\text { product } \\
\text { (bp) }\end{array}$ & $\begin{array}{l}\text { PCB } \\
\text { programs }\end{array}$ & PCR volume $(50 \mu \mathrm{L})$ \\
\hline & & & & $\frac{72^{0 \mathrm{C}}}{-4 \mathrm{~min}}$ & \\
\hline & & & & 1 cycle: & $5 \mu \mathrm{L}$ DNA template \\
\hline & & & & $\begin{array}{l}72^{\circ \mathrm{C}} \\
-7 \mathrm{~min}\end{array}$ & \\
\hline \multirow[t]{2}{*}{ TSST-1 } & \multirow{2}{*}{$\begin{array}{l}\text { Toxic Shock } \\
\text { Syndrome Toxin }\end{array}$} & F: ATGGCAGCATCAGCTTGATA & \multirow[t]{2}{*}{350} & 1 cycle: & $5 \mu \mathrm{L}$ PCR buffer $10 \mathrm{X}$ \\
\hline & & R: TTTCCAATAACCACCCGTTT & & $94^{\circ C}$ & $2 \mathrm{mM} \mathrm{Mgcl}_{2}$ \\
\hline \multirow[t]{7}{*}{ eta } & \multirow[t]{7}{*}{ exfoliative toxins $\mathrm{A}$} & F: CTAGTGCATTTGTTATTCAA & \multirow[t]{7}{*}{119} & $-6 \mathrm{~min}$. & $200 \mu \mathrm{M} d N T P$ \\
\hline & & R: TGCATTGACACCATAGTACT & & 30 cycle: & $0.5 \mu \mathrm{M}$ of each primers $\mathrm{F} \& \mathrm{R}$ \\
\hline & & & & $\begin{array}{l}94 \mathrm{OC} \\
-2 \mathrm{~min}\end{array}$ & 1.5 U Taq DNA polymerase \\
\hline & & & & $\begin{array}{l}55^{\circ \mathrm{C}} \\
-2 \mathrm{~min}\end{array}$ & $5 \mu \mathrm{L}$ DNA template \\
\hline & & & & $\underline{72}{ }^{0 \mathrm{C}} \mathrm{min}$ & \\
\hline & & & & 1 cycle: & \\
\hline & & & & $\begin{array}{l}72^{\circ \mathrm{C}} \\
-8 \mathrm{~min}\end{array}$ & \\
\hline \multirow[t]{8}{*}{$p v l$} & \multirow[t]{8}{*}{$\begin{array}{l}\text { Panton-Valentine } \\
\text { leucocidin }\end{array}$} & $\begin{array}{l}\text { F: } \\
\text { ATCATTAGGTAAAATGTCTGGACATGATCCA }\end{array}$ & \multirow[t]{8}{*}{433} & 1 cycle: & \\
\hline & & \multirow[t]{7}{*}{ R: GCATCAASTGTATTGGATAGCAAAAGC } & & $94^{0 \mathrm{C}}-5 \mathrm{~min}$. & \\
\hline & & & & 30 cycle: & 200 pivi aivis \\
\hline & & & & $940 \mathrm{c}$ & 1.5 U Taq DNA polymerase \\
\hline & & & & $\frac{56}{-0 \mathrm{C}}$ & $5 \mu \mathrm{L}$ DNA template \\
\hline & & & & $72^{\circ \mathrm{CC}}$ & \\
\hline & & & & 1 cycle: & \\
\hline & & & & $\underline{72}$ oc $10 \mathrm{~min}$ & \\
\hline
\end{tabular}

\begin{tabular}{|c|c|c|c|c|c|}
\hline \multirow[t]{4}{*}{ hla } & \multirow[t]{4}{*}{ hemolysin } & F: CTGATTACTATCCAAGAAATTCGATTG & \multirow[t]{4}{*}{209} & 1 cycle: & $5 \mu \mathrm{L}$ PCR buffer $10 \mathrm{X}$ \\
\hline & & \multirow[t]{3}{*}{ R: CTTTCCAGCCTACTTTTTTTATCAGT } & & $94^{\circ \mathrm{CC}}$ & \\
\hline & & & & 30 cyce. & $200 \mu \mathrm{M}$ dNTP \\
\hline & & & & & $0.5 \mu \mathrm{M}$ of each primers $\mathrm{F} \& \mathrm{R}$ \\
\hline \multicolumn{4}{|c|}{ a $\mathrm{R}$ is $\mathrm{A}$ or $\mathrm{G}$; $\mathrm{Y}$ is $\mathrm{C}$ or $\mathrm{T}$; $\mathrm{S}$ is $\mathrm{G}$ or $\mathrm{C}$. } & $\begin{array}{l}94^{\circ \mathrm{C}} \\
-30 \mathrm{~s}\end{array}$ & 1.5 U Taq DNA polymerase \\
\hline
\end{tabular}




\begin{tabular}{|c|c|c|c|c|c|}
\hline $\begin{array}{l}\text { Target } \\
\text { gene }\end{array}$ & Encoding antibiotic & Primer sequence $\left(5^{\prime}-3^{\prime}\right)$ & $\begin{array}{l}\text { PCR } \\
\text { product } \\
\text { (bp) }\end{array}$ & $\begin{array}{l}\text { PCRc } \\
\text { programs }\end{array}$ & BCR Dolluntren(50apt) \\
\hline & & & & $\begin{array}{l}72^{\mathrm{OC}} \\
-1 \mathrm{~min} \\
1 \text { cycle: } \\
72^{\mathrm{OC}} \\
-10 \mathrm{~min}\end{array}$ & \\
\hline$f n b A$ & $\begin{array}{l}\text { Fibronectin-binding } \\
\text { protein }\end{array}$ & $\begin{array}{l}\text { F: GTGAAGTTTTAGAAGGTGGAAAGATTAG } \\
\text { R: GCTCTTGTAAGACCATTTTTCTTCAC }\end{array}$ & 643 & $\begin{array}{l}1 \text { cycle: } \\
94 \text { oc } \\
-5 \mathrm{~min} . \\
30 \text { cycle: } \\
940 \mathrm{c} \\
-30 \mathrm{~s} \\
57 \text { oc } \\
-40 \mathrm{~s} \\
72 \text { oc } \\
-1 \mathrm{~min} \\
1 \mathrm{cycle}: \\
72 \text { oc } \\
-10 \mathrm{~min}\end{array}$ & $\begin{array}{l}5 \mu \mathrm{L} \text { PCR buffer } 10 \mathrm{X} \\
2 \mathrm{mM} \mathrm{Mgcl} 2 \\
200 \mu \mathrm{M} \text { dNTP } \\
0.5 \mu \mathrm{M} \text { of each primers } \mathrm{F} \& \mathrm{R} \\
1.5 \mathrm{U} \text { Taq DNA polymerase } \\
5 \mu \mathrm{L} \text { DNA template }\end{array}$ \\
\hline
\end{tabular}

\section{RAPD molecular typing of MRSA strains}

RAPD-PCR molecular typing of MRSA isolates was performed according to the previously recorded method [29]. Three oligonucleotides of OLP6 (5'GAGGGAAGAG-3'), OLP11 (5'-ACGATGAGCC-3'), and OLP13 (5'-ACCGCCTGCT-3') (60-70\% of G-C content) were used for amplification. Cycles of amplification were included $94{ }^{\circ} \mathrm{C}$ for $5 \mathrm{~min}$, followed by 40 cycles of $93^{\circ} \mathrm{C}$ for $60 \mathrm{~s}, 37^{\circ} \mathrm{C}$ for $90 \mathrm{~s}$ and $72{ }^{\circ} \mathrm{C}$ for $60 \mathrm{~s}$, and a $72{ }^{\circ} \mathrm{C}$ for 8 min final extension. Electrophoresis was performed using a $1.5 \%$ agarose gel. Gel images were analyzed using GelWorks 1D software (version 3.00, England). Similarity percent was examined. Cluster analysis of similarity matrices was performed by the unweighted pair group method with arithmetic averages (UPGMA). The NTSYS-pc software (version 2.01e, Applied Biostatistics, NY, USA) was used. The analysis was performed using the methods labeled previously [30].

\section{Statistical analysis}

Statistical analysis was done using the SPSS 21.0 statistical software (SPSS Inc., Chicago, IL, USA). Chi-square test and Fisher's exact two-tailed test were used to assess any significant relationship between the phenotypic and genotypic properties of antibiotic resistance, distribution of virulence factors of the MRSA bacteria isolated from vegetable and salad samples. Student's t-test was used to assess statistical significance between RAPD clusters. $P$-value $<0.05$ was considered a statistically significant level.

\section{Results}

\section{Prevalence of S. aureus and MRSA isolates amid the vegetable and salad samples}

The present examination was addressed to assess the prevalence rate, antibiotic resistance properties, virulence characters, and molecular typing of MRSA bacteria recovered from vegetable and salad samples.

Table 2 discloses the prevalence of $S$. aureus and MRSA bacteria amid examined vegetable and salad samples. Forty-five out of 350 (12.85\%) vegetable and salad samples were contaminated with $S$. aureus. The total contamination rate of vegetable and salad samples with the $S$. aureus bacteria was $9.44 \%$ and $16.47 \%$, respectively. A statistically significant difference was obtained for the prevalence of $S$. aureus amid vegetables and salads $(P<0.05)$. Twenty-six isolates out of $45(57.77 \%)$ S. aureus bacteria simultaneously resisted cefoxitin and oxacillin antibiotic disks.

Table 2

Prevalence of $S$. aureus and MRSA bacteria amid examined vegetable and salad samples.

\begin{tabular}{|llll|}
\hline Samples & N. collected samples & N. samples positive for S. aureus $(\%)$ & N. S. aureus isolates determined as MRSA (\%) \\
\hline Vegetable & 180 & $17(9.44)$ & $8(47.05)$ \\
\hline Salad & 170 & $28(16.47)$ & $18(64.28)$ \\
\hline Total & 350 & $45(12.85)$ & $26(57.77)$ \\
\hline
\end{tabular}


Additionally, all of them harbored the mecA gene. Thus, the total prevalence of MRSA strains amid the $S$. aureus bacteria was $57.77 \%$. A statistically significant difference was obtained for MRSA prevalence amid vegetables and salads $(P<0.05)$.

\section{Phenotypical assessment of antibiotic resistance of MRSA isolates}

Table 3 discloses the phenotypic pattern of antibiotic resistance of MRSA bacteria isolated from vegetable and salad samples. MRSA bacteria exhibited the uppermost prevalence of resistance toward cefoxitin (100\%), ceftaroline (100\%), penicillin (100\%), tetracycline (88.46\%), gentamicin (80.76\%), trimethoprimsulfamethoxazole (69.23\%), and erythromycin (69.23\%) antibiotic agents. Reversely, MRSA bacteria harbored the lowermost prevalence of resistance toward nitrofurantoin (30.76\%), rifampin (34.61\%), doxycycline (38.46\%), quinupristin-dalfopristin (38.46\%), and vancomycin (42.30\%). MRSA bacteria isolated from salad samples harbored a higher prevalence of resistance toward all examined antibiotic agents than vegetables $(P<0.05)$.

Table 3

The phenotypic pattern of antibiotic resistance of MRSA bacteria isolated from vegetable and salad samf

\begin{tabular}{|c|c|c|c|c|c|c|c|c|c|c|c|}
\hline \multirow{3}{*}{$\begin{array}{l}\text { Type of } \\
\text { samples } \\
\text { (N. } \\
\text { MRSA) }\end{array}$} & \multicolumn{11}{|c|}{$\mathbf{N}(\%)$ isolates resistant to each antibiotic } \\
\hline & \multirow{2}{*}{$\begin{array}{l}\text { Streptogramins } \\
\text { Qun-DIf* }\end{array}$} & \multicolumn{2}{|c|}{ Macrolides } & \multicolumn{2}{|c|}{ Cephems } & \multirow{2}{*}{$\begin{array}{l}\text { Aminoglycosides } \\
\text { Gen }\end{array}$} & \multicolumn{2}{|c|}{ Fluoroquinolones } & \multirow{2}{*}{$\begin{array}{l}\text { folate } \\
\text { pathway } \\
\text { antagonists } \\
\text { Tr-sul }\end{array}$} & \multirow{2}{*}{$\begin{array}{l}\text { Penicillins } \\
\text { P10 }\end{array}$} & \multirow{2}{*}{$\begin{array}{l}\text { Ansamycins } \\
\text { Rif }\end{array}$} \\
\hline & & Azi & Ery & Cfx & Cft & & Cip & Lev & & & \\
\hline $\begin{array}{l}\text { Vegetable } \\
\text { (8) }\end{array}$ & $2(25)$ & $4(50)$ & $\begin{array}{l}5 \\
(62.50)\end{array}$ & $\begin{array}{l}8 \\
(100)\end{array}$ & $\begin{array}{l}8 \\
(100)\end{array}$ & $6(75)$ & $4(50)$ & $\begin{array}{l}4 \\
(50)\end{array}$ & $5(62.50)$ & $8(100)$ & $2(25)$ \\
\hline $\begin{array}{l}\text { Salad } \\
(18)\end{array}$ & $8(44.44)$ & $\begin{array}{l}11 \\
(61.11)\end{array}$ & $\begin{array}{l}13 \\
(72.22)\end{array}$ & $\begin{array}{l}18 \\
(100)\end{array}$ & $\begin{array}{l}18 \\
(100)\end{array}$ & $15(83.33)$ & $\begin{array}{l}11 \\
(61.11)\end{array}$ & $\begin{array}{l}9 \\
(50)\end{array}$ & $13(72.22)$ & $18(100)$ & $7(38.88)$ \\
\hline Total (26) & $10(38.46)$ & $\begin{array}{l}15 \\
(57.69)\end{array}$ & $\begin{array}{l}18 \\
(69.23)\end{array}$ & $\begin{array}{l}26 \\
(100)\end{array}$ & $\begin{array}{l}26 \\
(100)\end{array}$ & $21(80.76)$ & $\begin{array}{l}15 \\
(57.69)\end{array}$ & $\begin{array}{l}13 \\
(50)\end{array}$ & $18(69.23)$ & $26(100)$ & $9(34.61)$ \\
\hline
\end{tabular}

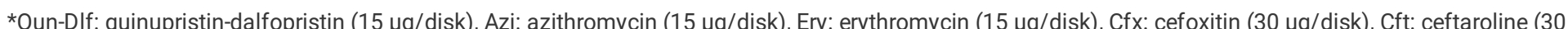
ciprofloxacin ( $5 \mu \mathrm{g} /$ disk), Lev: levofloxacin (5 $\mathrm{g}$ /disk), Tr-Sul: trimethoprim-sulfamethoxazole (1.25/23.75 $\mu \mathrm{g} / \mathrm{disk})$, P10: penicillin (10 units/disk), Rif: rifamf tetracycline (30 $\mu \mathrm{g} / \mathrm{disk})$, Dox: doxycycline (30 $\mu \mathrm{g} / \mathrm{disk})$, and nitrofurantoin $(300 \mu \mathrm{g} / \mathrm{disk})$.

\section{Prevalence of multidrug resistant-MRSA}

Figure 1 describes the prevalence of multidrug resistant-MRSA bacteria amongst vegetable samples. All MRSA bacteria isolated from vegetable samples harbored resistance to at least three examined antibiotic agents (100\%). The prevalence of resistance toward at least four antibiotic agents was $75 \%$. Totally, $12.50 \%$ of the MRSA isolates harbored resistance toward more than 7 antibiotic agents.

Figure 2 describes the prevalence of multidrug resistant-MRSA bacteria amongst salad samples. All MRSA bacteria isolated from salad samples harbored resistance to at least three examined antibiotic agents (100\%). The prevalence of resistance toward at least four antibiotic agents was $88.88 \%$. Totally, $27.77 \%$ of the MRSA isolates harbored resistance toward more than seven antibiotic agents.

\section{Genotypical assessment of antibiotic resistance of MRSA isolates}

Table 4 described the genotypic pattern of antibiotic resistance of MRSA bacteria isolated from vegetable and salad samples. MRSA isolates were genotypically harbored higher distribution of blaCTX-M (100\%), blaZ (100\%), aacA-D (61.53\%), tetK (57.69\%), dfrA1 (46.15\%), and vanA (42.30\%). Reversely, the prevalence of tetM (19.23\%), rpoB (19.23\%), vatA (23.07\%), and grlA (30.76\%) were lower than other examined antibiotic resistance genes. MRSA bacteria isolated from salad samples harbored a higher prevalence of antibiotic resistance genes than vegetables $(P<0.05)$. Statistically, a significant difference was gotten amid the distribution of tetK and $\operatorname{tet} M(P<0.05)$ antibiotic resistance genes.

Table 4

The genotypic pattern of antibiotic resistance of MRSA bacteria isolated from vegetable and salad samples.

\begin{tabular}{|c|c|c|c|c|c|c|c|c|c|c|c|}
\hline \multirow{3}{*}{$\begin{array}{l}\text { Type of } \\
\text { samples } \\
\text { (N. } \\
\text { MRSA) }\end{array}$} & \multicolumn{11}{|c|}{$\mathrm{N}(\%)$ isolates harbored each antibiotic resistance gene } \\
\hline & \multirow{2}{*}{$\begin{array}{l}\text { Streptogramins } \\
\text { vatA }\end{array}$} & \multicolumn{2}{|c|}{ Macrolides } & \multirow{2}{*}{$\begin{array}{l}\text { Cephems } \\
\text { blactX- } \\
\text { M }\end{array}$} & \multirow{2}{*}{$\begin{array}{l}\text { Aminoglycosides } \\
\text { aacA-D }\end{array}$} & \multicolumn{2}{|c|}{ Fluoroquinolones } & \multirow{2}{*}{$\begin{array}{l}\begin{array}{l}\text { Folate } \\
\text { pathway } \\
\text { antagonists }\end{array} \\
\text { dfrA1 }\end{array}$} & \multirow{2}{*}{$\begin{array}{l}\text { Penicillins } \\
\text { blaz }\end{array}$} & \multirow{2}{*}{$\begin{array}{l}\text { Ansamycins } \\
\text { rpoB }\end{array}$} & \multirow{2}{*}{$\begin{array}{l}\text { Gly } \\
\text { va }\end{array}$} \\
\hline & & $e r m A$ & $m s r A$ & & & gyrA & grlA & & & & \\
\hline $\begin{array}{l}\text { Vegetable } \\
\text { (8) }\end{array}$ & $1(12.50)$ & $2(25)$ & $2(25)$ & $8(100)$ & $4(50)$ & $2(20)$ & $2(25)$ & $2(25)$ & $8(100)$ & $1(12.50)$ & $3(3$ \\
\hline $\begin{array}{l}\text { Salad } \\
\text { (18) }\end{array}$ & $5(62.50)$ & $\begin{array}{l}7 \\
(38.88)\end{array}$ & $\begin{array}{l}8 \\
(44.44)\end{array}$ & $18(100)$ & $12(66.66)$ & $\begin{array}{l}8 \\
(44.44)\end{array}$ & $\begin{array}{l}6 \\
(33.33)\end{array}$ & $10(55.55)$ & $18(100)$ & $4(50)$ & 8( \\
\hline Total (26) & $6(23.07)$ & $\begin{array}{l}9 \\
(34.61)\end{array}$ & $\begin{array}{l}10 \\
(38.46)\end{array}$ & $26(100)$ & $16(61.53)$ & $\begin{array}{l}10 \\
(38.46)\end{array}$ & $\begin{array}{l}8 \\
(30.76)\end{array}$ & $12(46.15)$ & $26(100)$ & $5(19.23)$ & 11 \\
\hline
\end{tabular}

\section{Distribution of virulence factors amongst the MRSA isolates}


Table 5 described the distribution of virulence factors amongst the MRSA bacteria isolated from vegetable and salad samples. $P V L$ ( $57.69 \%)$, coa (53.84\%), and $h / a(38.46 \%)$ were the most commonly detected virulence factors amongst the MRSA bacteria isolated from vegetable and salad samples. The total prevalence of $f n b A$, etA, and tsst- 1 virulence factors amongst the MRSA isolates were $34.61 \%, 23.07 \%$, and $11.53 \%$, respectively. MRSA bacteria isolated from salad samples harbored the higher prevalence of antibiotic resistance genes than those of vegetables $(P<0.05)$.

Table 5

Profile of virulence factors of the MRSA bacteria isolated from vegetable and salad samples.

\begin{tabular}{|c|c|c|c|c|c|c|}
\hline \multirow{3}{*}{$\begin{array}{l}\text { Type of samples (N. } \\
\text { MRSA) }\end{array}$} & \multicolumn{6}{|c|}{$\mathrm{N}(\%)$ isolates harbored each virulence factors } \\
\hline & Coagulase & $\begin{array}{l}\text { Toxic Shock Syndrome } \\
\text { Toxin }\end{array}$ & $\begin{array}{l}\text { Exfoliative } \\
\text { toxins A }\end{array}$ & $\begin{array}{l}\text { Panton-Valentine } \\
\text { leucocidin }\end{array}$ & Hemolysin & $\begin{array}{l}\text { Fibronectin-binding } \\
\text { protein }\end{array}$ \\
\hline & coa & tsst-1 & eta & $P V L$ & hla & $f n b A$ \\
\hline Vegetable (8) & $2(25)$ & - & $1(12.50)$ & $3(37.50)$ & $2(25)$ & $2(25)$ \\
\hline Salad (18) & $12(66.66)$ & $3(16.66)$ & $5(27.77)$ & $12(66.66)$ & $8(44.44)$ & $7(38.88)$ \\
\hline Total (26) & $14(53.84)$ & $3(11.53)$ & $6(23.07)$ & $15(57.69)$ & $10(38.46)$ & $9(34.61)$ \\
\hline
\end{tabular}

\section{RAPD-PCR molecular typing of MRSA isolates}

Figure 1 exhibits the RAPD-PCR molecular typing of MRSA strains isolated from vegetable and salad samples. All MRSA isolates had a similarity lower than $80 \%$ (except isolating No 10) and were categorized in the same group. MRSA isolates. No 10 had a $100 \%$ genetic difference with other isolates. Among other isolates, $15.4-87.5 \%$ similarities were observed.

\section{Discussion}

It is indispensable to distinguish the exact routes of transmission of antibiotic-resistant bacteria to the human population from the epidemiological perspective. Foods have a critical role in transmitting some types of antibiotic resistant-bacteria to humans [31-33]. Vegetables and salad are two of the most important and highly consumed foodstuffs worldwide [3,34]. They are considered a ubiquitous source of antibiotic-resistant-S. aureus [35, 36].

An existing survey was aimed to assess the molecular typing and phenotypic and genotypic assessment of antibiotic resistance and virulence factors of the MRSA bacteria isolated from vegetable and salad samples. The total prevalence of MRSA bacteria amongst the vegetable and salad samples was $4.44 \%$ $(8 / 180)$ and $10.58 \%(18 / 170)$, respectively. The present research is the first report of isolation of MRSA bacteria from vegetable and salad samples. Cesar et al. (2015) [37] described that the total prevalence of coagulase-negative and -positive staphylococci amongst the lettuce salad samples collected from Brazil were $77.80 \%$ and $5.60 \%$, respectively. Osiriphun, Poonlarp, and Boonyakiat [38] stated that $S$. aureus is one of the most prevalent causes of contamination of mixed salad vegetables in Thailand. Total prevalence of $S$. aureus amongst the vegetable and salad samples collected from Argentina [39], Brazil [40], Zambia [41], Korea [42], Pakistan [11], Saudi Arabia [43], and India [44] were $7.81 \%, 43.80 \%, 60 . \%, 11.30 \%, 54 \%, 51.50 \%$, and $86 \%$, respectively. Close contact of the vegetable samples with the contaminated animal- and even human-based fertilizers and water used for their growth and irrigation and contaminated soil is a probable reason for MRSA presence. Survival of bacteria from farm to fork and the transmission of MRSA bacteria from contaminated restaurants to salad samples are probable reasons for the higher prevalence of bacteria in salads. S. aureus is present in soil, feces, sewage, and water, and characteristically originates from contact with vegetables by means of the water used for their growing. The bacterium can contaminate salads on account of poor hygienic circumstances of farmers, retailers, and food processer and vendors. Furthermore, the bacterium can distribute by straight contact throughout harvesting, processing, and packing. Another probable reason for the higher prevalence of $S$. aureus in salad samples is that $S$. aureus cannot compete well with indigenous microflora of vegetables. Both vegetable and salad samples have optimum growth circumstances for $S$. aureus $(\mathrm{pH}(4.8-9.3)$ and temperatures $\left(7-43^{\circ} \mathrm{C}\right)$ ). Thus, it is not surprising that $12.85 \%$ of samples were contaminated with $S$. aureus.

Our survey revealed that MRSA bacteria isolated from vegetable and salad samples harbored high resistance toward cefoxitin, ceftaroline, penicillin, tetracycline, gentamicin, trimethoprim-sulfamethoxazole, and erythromycin antibiotic agents, which was assisted with a high prevalence of $b / a C T X-M, b / a Z$, aacA-D, tetK, dfrA1, and vanA antibiotic resistance genes. Otherwise, phenotypic assessment of antibiotic resistance of MRSA bacteria was confirmed by the genotypic evaluation of the resistance gene. Furthermore, the presence of multidrug resistant-MRSA was found in some isolates. Irregular and unauthorizing antibiotic agents' prescription is the probable reason for the high prevalence of resistance and high distribution of antibiotic resistance genes. Findings disclosed that some MRSA bacteria isolated from salad samples exhibited a higher prevalence of resistance toward antibiotic agents used to treat human clinical infections, which can indirectly signify that they may transmit from infected staff and workers of restaurants. The high prevalence of resistance of MRSA bacteria isolated from vegetable samples toward antibiotic agents used for the treatment of animal clinical infections may show their transmission from animal-based fertilizers and even contaminated water used for the growth of vegetable samples. According to the literature, the current research is the first report of the phenotypic and genotypic assessments of antibiotic resistance among MRSA bacteria isolated from vegetable and salad samples. Wu et al. (2018) [45] described that the antibiotic resistance of $S$. aureus bacteria isolated from vegetable in China against amoxicillin/clavulanic acid, ampicillin, cefepime, cefoxitin, penicillin, ceftazidime, amikacin, gentamicin, kanamycin, streptomycin, chloramphenicol, clindamycin, erythromycin, telithromycin, ciprofloxacin, norfloxacin, tetracycline, linezolid, rifampicin, trimethoprim/sulphamethoxazole, quinupristin/dalfopristin, teicoplanin, nitrofurantoin and fusidic acid were $26.70 \%, 93.30 \%, 10 \%, 16.70 \%, 93.30 \%, 16.70 \%, 3.30 \%, 16.70 \%, 33.30 \%, 23.30 \%, 23.30 \%, 23.30 \%, 40 \%, 20 \%, 23.30 \%, 16.70 \%, 43.30 \%, 0 \%, 0 \%, 0 \%$, $3.30 \%, 0 \%, 0 \%$ and $10 \%$, respectively. Similarly, SergeliDiS et al. (2012) [46] stated that the prevalence of resistance of S. aureus bacteria isolated from readyto-eat salads in Greece against ampicillin, chloramphenicol, clindamycin, erythromycin, fosfomycin, gentamicin, penicillin, quinupristin/dalfopristin, rifampin, and trimethoprim/sulfamethoxazole antibiotic agents were $94 \%, 3 \%, 1.50 \%, 89.40 \%, 82.60 \%, 4.50 \%, 59.10 \%, 1.50 \%, 1.50 \%$, and $1.50 \%$, respectively. Similar to our findings, a high prevalence of resistance of $S$. aureus bacteria isolated from vegetables and salads and other foodstuffs and clinical infections against

Page $10 / 19$ 
cefoxitin, ceftaroline, penicillin, tetracycline, gentamicin, trimethoprim-sulfamethoxazole, and erythromycin antibiotic agents were reported from Iran [9, 4750], Nigeria [51], China [52], Korea [42], and the United States [53]. The presence of antibiotic resistance genes was not examined in the MRSA bacteria isolated from vegetable and salad samples previously. Dehkordi, Gandomi, Basti, Misaghi and Rahimi [54] revealed that the prevalence of aacA-D, tetK, tetM, $m s r A$, ermA, ermC, vatA, vatB, vatC, and linA amongst the MRSA bacteria isolated from hospital food samples were $62.16 \%, 72.97 \%, 27.02 \%, 64.86 \%, 72.97 \%$, $27.02 \%, 45.94 \%, 18.91 \%, 5.40 \%$, and $43.24 \%$, respectively. In the same way, Rahi et al. (2020) [55] disclosed that the prevalence of $b l a Z$, aacA-D, ermA, ermB, msrA, msrB, mefA, tetK, tetM, gyrA, grlA, linA, dfrA1, cfr, and rpoB amongst the MRSA bacteria isolated from raw milk samples were $100 \%, 67.85 \%, 50 \%, 25 \%$, $35.71 \%, 10.71 \%, 35.71 \%, 85.71 \%, 35.71 \%, 42.85 \%, 28.57 \%, 28.75 \%, 71.42 \%, 25 \%$, and $10.71 \%$, respectively. Our findings were also released a higher prevalence of phenotypic profile of resistance than the genotypic pattern. For instance, all of the glycopeptides-resistant MRSA bacteria didn't harbor vanA antibiotic resistance gene. This matter has also existed for other antibiotic agents and resistance genes. This finding is maybe because antibiotic resistance genes are one of the known procedures for the occurrence of antibiotic resistance in MRSA strains. Otherwise, different mechanisms have been recognized to induce antibiotic resistance in bacteria, including efflux antibiotic's active pumps to out of the bacterial cell, reduced permeability of bacteria to antibiotics, inactivation of antibiotics through hydrolysis or changes in their structure, change in antibiotic target site, access of bacteria to the secondary metabolic pathways that compensate the antibiotic-inhibited reactions and occurrence of genetic mutations. Discoveries also showed the high prevalence of multidrug resistant-MRSA strains amongst examined samples, particularly salads. In the same way, high prevalence of multidrug-resistant bacteria has been reported in herbal product samples in Cameron [56], Kuwait [57], and Tanzania [58]. Altogether, high prevalence of antibiotic resistant-MRSA which was accompanying with the high distribution of antibiotic resistance genes and presence of multidrug resistance disclosed an imperative public health issue regarding the consumption of vegetable and salad samples. Given that these antibiotics have been progressively utilized in human and animal treatments and the exchange of antibiotic-resistant genes by the mobile genetic elements, it is not astonishing that resistant bacteria become more mutual nowadays. Nevertheless, the high antimicrobial resistance of MRSA observed in this research should receive much attention. Furthermore, controlled use of antimicrobials would limit the emergence of drug-resistant bacteria.

Findings described the considerable prevalence of virulence factors amongst the MRSA bacteria isolated from vegetable and salad samples. Alpha-hemolysin ( $h / a$ ) toxin is the most emphasized virulence factor of the S. aureus, which is considered a candidate of vaccine to inhibit the dissemination of infections [59]. Most $S$. aureus bacteria recovered from clinical infections and, more recently, food samples, harbored the coa factor [60]. It mainly acts as a blood coagulase factor in the pathogenesis of staphylococcal infections [60]. PVL is cytotoxin responsible for severe tissue necrosis and leukocyte destruction [61]. PVL, coa, and hla virulence factors also had high prevalence amongst the $S$. aureus bacteria isolated from food and clinical samples collected from Egypt [62], Myanmar [63], China [59], Iran [64], and Brazil [65]. The high prevalence of identified virulence factors in the MRSA bacteria of this research may show high virulence and pathogenicity of MRSAS bacteria, which poses an imperative public health hazard rendering the consumption of contaminated vegetable and salad samples. Assess the PVL gene's distribution is one of the essential practical methods to find the presence of healthcare-associated (HA-) or communityassociated (CA) MRSA bacteria. Findings of epidemiological investigations revealed that the CA-MRSA bacteria mainly carry the $P V L$ gene [63]. In the present research, $37.50 \%$ of MRSA bacteria isolated from vegetable samples and $66.66 \%$ of those of salad samples harbored the $P V L$ gene. Thus, majority of MRSA bacteria isolated from vegetable samples may categorized as HA-MRSA, while majority of those of salad samples may categorized as CA-MRSA. However, assessment of the presence of Staphylococcal Cassette Chromosome mec (SCCmec) may clear the exact type of MRSA isolates.

Molecular typing of MRSA bacteria showed that they had a similarity lower than $80 \%$ (except isolate No 10), which may show that they have the same genetic cluster. This matter may show the expected contamination of vegetable and salad samples with MRSA bacteria with the same molecular cluster.

\section{Conclusions}

In conclusion, MRSA presence in examined samples, accompanied by the high prevalence of resistance toward diverse classes of antibiotic agents and different antibiotic resistance genes and virulence factors, was reported in the current survey. To the best of the author's knowledge, the current survey is the first report of the assessment of antibiotic resistance properties, virulence characters, and molecular typing amongst the MRSA bacteria recovered from vegetable and salad samples. MRSA bacteria recovered from salad samples had a higher prevalence of antibiotic resistance, virulence factors, and antibiotic resistance genes. Simultaneous attendance of virulence factors and antibiotic resistance amongst the MRSA bacteria pose an imperative menace, rendering vegetable and salad samples the role of consuming vegetable and salad samples on the transmission of antibiotic-resistant and virulent MRSA bacteria. The prevalence of resistance toward human-based antibiotics can indirectly show the origin of MRSA isolates. It seems that cefoxitin, ceftaroline, penicillin, tetracycline, gentamicin, trimethoprim-sulfamethoxazole, and erythromycin are no effective therapeutic agents in the cases of $S$. aureus foodborne diseases in Iran. According to RAPD-PCR, all isolates had lower than $80 \%$ similarities and were categorized in the same cluster, showing their common contamination source. Put together, the findings of the present survey showed that vegetable and salad samples were significant sources of virulence and resistant MRSA bacteria in the community. According to the distribution of the PVL gene, most MRSA bacteria isolated from vegetables may be characterized as HA-MRSA, while most of those of salad samples may be characterized as CA-MRSA. However, further investigations may determine MRSA bacteria's exact role and characters amongst the vegetable and salad samples.

\section{Abbreviations}

\section{S. aureus}

Staphylococcus aureus; TSS:Toxic Shock Syndrome; MRSA:Methicillin-Resistant S. aureus, PVL:Panton-Valentine leucocidin; PCR:Polymerase Chain Reaction; SPSS:Statistical Package for the Social Sciences; CLSI:Clinical and Laboratory Standard Institute; RAPD:Randomly Amplified Polymorphic DNA; HAMRSA:healthcare-associated MRSA; CA-MRSA:community-associated MRSA.

\section{Declarations}


Ethics approval and consent to participate

The Ethical Council approved the study of Research of the Faculty of Veterinary Medicine, Shahrekord Branch, Islamic Azad University, Shahrekord, Iran. Verification of this research project and the licenses related to the sampling process were approved by Prof. Ebrahim Rahimi and Prof. Reza Ranjbar (Approval Ref Number 2019-789).

\section{Consent for publication}

There was no consent for publication.

\section{Availability of data and material}

All data generated or analyzed throughout this research are included in this published article.

\section{Competing interests}

The authors declare that they have no competing interests

\section{Funding}

The authors of the study supported this work.

\section{Authors' contributions}

FSD designed the study and carried out the PCR genetic alignment. MM, BT, BM, RR, ER, FD, SJ, MAK, ZM, and MAR supported the study and carried out the samples collection, culture-based identification, disk diffusion, DNA extraction, and statistical analysis. MM carried out the writing and drafting of the manuscript. All authors read and approved the final manuscript.

\section{Acknowledgments}

The authors aimed to thank the Food Hygiene Research Center of IAUSHK, Molecular Biology Research Center of the Baqiyatallah University of Medical Sciences, and Halal Research Center of the IRI, FDA, Tehran, Iran for the significant supports.

\section{Authors' information}

${ }^{1}$ Dietary Supplements and Probiotic Research Center, Alborz University of Medical Sciences, Karaj, Iran; ${ }^{2}$ Department of Physiology and Pharmacology, School pf Medicine, Alborz University of Medical Sciences, Karaj, Iran (B.tavakolifar@abzums.ac.ir). ${ }^{3}$ Department of Food Hygiene and Public Health, Shahrekord Branch, Islamic Azad University, Shahrekord, Iran (Uniqe_musavi@yahoo.com; Ebrahimrahimi55@yahoo.com). ${ }^{4}$ Department of Food Hygiene, Karaj Branch, Islamic Azad University, Karaj, Iran (Mashak@kiau.ac.ir). ${ }^{5}$ Department of Food Hygiene, Science and Research Branch, Islamic Azad University, Tehran, Iran (Rezaei_513@yahoo.com). ${ }^{6}$ Department of Microbiology, Faculty of Veterinary Medicine, University of Tehran, Tehran, Iran (Fdoregiraee@ut.ac.ir). ${ }^{7}$ Department of Agro-ecology, Shahrekord Branch, Islamic Azad University, Shareakord, Iran (Mehrdad.ataie@gmail.com). ${ }^{8}$ Department of Food Hygiene, Faculty of Veterinary Medicine, Shahrekord University, Shahrekord, Iran (M.momeni@iaushk.ac.ir). ${ }^{9}$ Halal Research Center of IRI, FDA, Tehran, Iran (F.safarpoor@ut.ac.ir). ${ }^{10}$ Molecular Biology Research Center, Systems Biology and Poisonings Institute, Baqiyatallah University of Medical Sciences, Tehran, Iran (Ranjbar@bmsu.ac.ir). ${ }^{11}$ Department of Parasitology, Faculty of Veterinary Medicine, University of Tehran, Tehran, Iran (Jjaaffaarrii@ut.ac.ir).

\section{References}

1. Slavin JL, Lloyd B. Health benefits of fruits and vegetables. Advances in nutrition. 2012;3:506-16.

2. Ghorbani F, Gheisari E, Dehkordi FS. Genotyping of vacA alleles of Helicobacter pylori strains recovered from some Iranian food items. Tropic J Pharma Res. 2016;15:1631-6.

3. Yahaghi E, Khamesipour F, Mashayekhi F, Safarpoor Dehkordi F, Sakhaei MH, Masoudimanesh M, Khameneie MK. Helicobacter pylori in vegetables and salads: genotyping and antimicrobial resistance properties. BioMed Res Int. 2014;2014:1-11.

4. Ranjbar R, Masoudimanesh M, Dehkordi FS, Jonaidi-Jafari N, Rahimi E. Shiga (Vero)-toxin producing Escherichia coli isolated from the hospital foods; virulence factors, o-serogroups and antimicrobial resistance properties. Antimicrob Resist Infect Control. 2017;6:1-11.

5. Safarpoor Dehkordi F, Basti AA, Gandomi H, Misaghi A, Rahimi E. Retracted: Pathogenic Staphylococcus aureus in hospital food samples; prevalence and antimicrobial resistance properties. J Food Safe. 2018;38:e12501.

6. Safarpoor Dehkordi F, Akhondzadeh Basti A, Gandomi H, Misaghi A, Rahimi E. Pathogenic Staphylococcus aureus in hospital food samples; prevalence and antimicrobial resistance properties. J Food Safe. 2018;e12501.

7. Safarpoor Dehkordi F, Gandomi H, Akhondzadeh Basti A, Misaghi A, Rahimi E. Phenotypic and genotypic characterization of antibiotic resistance of methicillin-resistant Staphylococcus aureus isolated from hospital food. Antimicrob Resist Infect Control. 2017;6:104.

8. Hasanpour Dehkordi A, Khaji L, Sakhaei Shahreza M, Mashak Z, Safarpoor Dehkordi F, Safaee Y, Hosseinzadeh A, Alavi I, Ghasemi E, Rabiei-Faradonbeh M. One-year prevalence of antimicrobial susceptibility pattern of methicillin-resistant Staphylococcus aureus recovered from raw meat. Tropic Biomed. 2017;34:396-404. 
9. Momtaz H, Dehkordi FS, Rahimi E, Asgarifar A, Momeni M. Virulence genes and antimicrobial resistance profiles of Staphylococcus aureus isolated from chicken meat in Isfahan province, Iran. J App Poultry Res. 2013;22:913-21.

10. Abakari G, Cobbina SJ, Yeleliere E. Microbial quality of ready-to-eat vegetable salads vended in the central business district of Tamale, Ghana. Int J Food Contamin. 2018;5:1-9.

11. Saifullah S, Abbas F, Samad A, Rizwan M, Bugti FS, Saima R, Yousaf M, Mykhaylo T, Raziq A. 31. Staphylococcus aureus prevalence in the fresh salad and vegetables of the Quetta city. Pure App Biol. 2018;7:255-62.

12. Gajdács M. The continuing threat of methicillin-resistant Staphylococcus aureus. Antibiotics. 2019;8:1-27.

13. Turner NA, Sharma-Kuinkel BK, Maskarinec SA, Eichenberger EM, Shah PP, Carugati M, Holland TL, Fowler VG. Methicillin-resistant Staphylococcus aureus: an overview of basic and clinical research. Nature Rev Microbiol. 2019;17:203-18.

14. Klevens RM, Morrison MA, Nadle J, Petit S, Gershman K, Ray S, Harrison LH, Lynfield R, Dumyati G, Townes JM. Invasive methicillin-resistant Staphylococcus aureus infections in the United States. Jama. 2007;298:1763-71.

15. Otarigho B, Falade MO. Analysis of antibiotics resistant genes in different strains of Staphylococcus aureus. Bioinformation. 2018;14:113-22.

16. Bukowski M, Wladyka B, Dubin G. Exfoliative toxins of Staphylococcus aureus. Toxins. 2010;2:1148-65.

17. Jenul C, Horswill AR. Regulation of Staphylococcus aureus virulence. Gram-Positive Pathogens. 2019;6:669-86.

18. Shallcross LJ, Fragaszy E, Johnson AM, Hayward AC. The role of the Panton-Valentine leucocidin toxin in staphylococcal disease: a systematic review and meta-analysis. Lancet Infect Dis. 2013;13:43-54.

19. Zare S, Derakhshandeh A, Haghkhah M, Naziri Z, Broujeni AM. Molecular typing of Staphylococcus aureus from different sources by RAPD-PCR analysis. Heliyon. 2019;5:e02231.

20. Fijałkowski K, Peitler D, Karakulska J. Staphylococci isolated from ready-to-eat meat-identification, antibiotic resistance and toxin gene profile. Int J Food Microbiol. 2016;238:113-20.

21. CLSI. Performance Standards for Antimicrobial Susceptibility Testing; 17th Informational Supplement. CLSI document M100-S17. 2007.

22. CLSI. Performance Standards for Antimicrobial Susceptibility Testing; Twenty-eight Informational Supplement. In. CLSI document M100. 2018.

23. Xuehan L, Fang F, Zhao J, Lou N, Li C, Huang T, Li Y. Molecular characteristics and virulence gene profiles of Staphylococcus aureus causing bloodstream infection. Brazilian J Infect Dis. 2018;22:487-94.

24. Strommenger B, Kettlitz C, Werner G, Witte W. Multiplex PCR assay for simultaneous detection of nine clinically relevant antibiotic resistance genes in Staphylococcus aureus. J Clin Microbiol. 2003;41:4089-94.

25. Lina G, Quaglia A, Reverdy M-E, Leclercq R, Vandenesch F, Etienne J. Distribution of genes encoding resistance to macrolides, lincosamides, and streptogramins among staphylococci. Antimicrob Agent Chemotherap. 1999;43:1062-6.

26. Aboshkiwa M, Rowland G, Coleman G. Nucleotide sequence of the Staphylococcus aureus RNA polymerase rpoB gene and comparison of its predicted amino acid sequence with those of other bacteria. Biochimica et Biophysica Acta (BBA)-Gene Structure and Expression. 1995;1262:73-8.

27. Schmitz F-J, Jones ME, Hofmann B, Hansen B, Scheuring S, Lückefahr M, Fluit A, Verhoef J, Hadding U, Heinz H-P. Characterization of grlA, grlB, gyrA, and gyrB mutations in 116 unrelated isolates of Staphylococcus aureus and effects of mutations on ciprofloxacin MIC. Antimicrob Agent Chemotherap. 1998;42:1249-52.

28. Pagani L, Dell'Amico E, Migliavacca R, D'Andrea MM, Giacobone E, Amicosante G, Romero E, Rossolini GM. Multiple CTX-M-type extended-spectrum $\beta$ lactamases in nosocomial isolates of Enterobacteriaceae from a hospital in northern Italy. J Clin Microbiol. 2003;41:4264-9.

29. Clark N, Cooksey R, Hill B, Swenson J, Tenover F. Characterization of glycopeptide-resistant enterococci from US hospitals. Antimicrob Agent Chemotherap. 1993;37:2311-7.

30. Reinoso E, Bettera S, Frigerio C, DiRenzo M, Calzolari A, Bogni C. RAPD-PCR analysis of Staphylococcus aureus strains isolated from bovine and human hosts. Microbiol Res. 2004;159:245-55.

31. Rahimi E, Yazdanpour S, Dehkordi F. Detection of Toxoplasma gondii antibodies in various poultry meat samples using enzyme linked immuno sorbent assay and its confirmation by polymerase chain reaction. J Pure Appl Microbiol. 2014;8:421-7.

32. Dehkordi FS, Valizadeh Y, Birgani T, Dehkordi K. Prevalence study of Brucella melitensis and Brucella abortus in cow's milk using dot enzyme linked immuno sorbent assay and duplex polymerase chain reaction. J Pure Appl Microbiol. 2014;8:1065-9.

33. Ranjbar R, Farsani FY, Dehkordi FS. Phenotypic analysis of antibiotic resistance and genotypic study of the vacA, cagA, iceA, oipA and babA genotypes of the Helicobacter pylori strains isolated from raw milk. Antimicrob Resist Infect Control. 2018;7:1-14.

34. Atapoor S, Dehkordi FS, Rahimi E. Detection of Helicobacter pylori in various types of vegetables and salads. Jundishapur J Microbiol. $2014 ; 7: 1-4$.

35. Najafi H, Mohammad B, Bahreini M. Microbiological quality of mixed fresh-cut vegetable salads and mixed ready-to-eat fresh herbs in Mashhad, Iran. International Conference on Nutrition and Food Sciences IPCBEE,(39). 2012;3962-6.

36. Hassan Z, Purwani E. Microbiological aspect of fresh produces as retailed and consumed in West Java, Indonesia. Int Food Res J. 2016;23:350-9.

37. César JG, Peres AM, das Neves CP, de Abreu ÉTF, de Mello JF, Moreira ÂN, Rodrigues KL. Microbiological assessment of lettuce salads and antimicrobial resistance of Staphylococcus spp. Nutricion Hospital. 2015;32:2280-5.

38. Osiriphun S, Poonlarp P, Boonyakiat D. Sensitivity analysis of Escherichia coli and Staphylococcus aureus of mixed salad vegetables during washing step at packing house. J Food Safe Hyg 2019; 5 (1): 51. 5:51-7.

39. Lucero Estrada CS, Alcaráz LE, Satorres SE, Manfredi E, Velázquez LdC. Presence of enterotoxigenic Staphylococcus aureus in artisan fruit salads in the city of San Luis, Argentina. Brazilian J Microbiol. 2013;44:1155-61.

Page 13/19 
40. Gomes Da Cruz MR, Barbalho DSLYJ, Julyanna DLM, Pavelquesi SLS, Luana Ribeiro DAO, Da Silva ICR, Orsi DC. Microbiological quality of minimally processed vegetables commercialized in Brasilia, DF, Brazil. Food Sci Technol. 2019;39:498-503.

41. Nguz K, Shindano J, Samapundo S, Huyghebaert A. Microbiological evaluation of fresh-cut organic vegetables produced in Zambia. Food control. 2005;16:623-8.

42. Seo Y-H, Jang J-H, Moon K-D. Occurrence and characterization of enterotoxigenic Staphylococcus aureus isolated from minimally processed vegetables and sprouts in Korea. Food Sci Biotechnol. 2010;19:313-9.

43. Hassan SA, Altalhi AD, Gherbawy YA, El-Deeb BA. Bacterial load of fresh vegetables and their resistance to the currently used antibiotics in Saudi Arabia. Foodborne Pathogen Dis. 2011;8:1011-8.

44. Ghosh M, Wahi S, Kumar M, Ganguli A. Prevalence of enterotoxigenic Staphylococcus aureus and Shigella spp. in some raw street vended Indian foods. Int J Env Health Res. 2007;17:151-6.

45. Wu S, Huang J, Wu Q, Zhang F, Zhang J, Lei T, Chen M, Ding Y, Xue L. Prevalence and characterization of Staphylococcus aureus isolated from retail vegetables in China. Front Microbiol. 2018;9:1-10.

46. SergeliDiS D, AbrAhim A, AnAgnoStou V, Govaris A, Papadopoulos T, Papa A. Prevalence, distribution, and antimicrobial susceptibility of Staphylococcus aureus in ready-to-eat salads and in the environment of a salad manufacturing plant in Northern Greece. Czech J Food Sci. 2012;30:285-91.

47. Abdolmaleki Z, Mashak Z, Dehkordi FS. Phenotypic and genotypic characterization of antibiotic resistance in the methicillin-resistant Staphylococcus aureus strains isolated from hospital cockroaches. Antimicrob Resist Infect Control. 2019;8:54.

48. Abdolmaleki Z, Mashak Z, Safarpoor Dehkordi F. Molecular and Virulence Characteristics of Methicillin-Resistant Staphylococcus aureus Bacteria Recovered From Hospital Cockroaches. Jundishapur J Microbiol. 2019;12.

49. Hasanpour Dehkordi A, Khaji L, Sakhaei Shahreza M, Mashak Z, Safarpoor Dehkordi F, Safaee Y, Hosseinzadeh A, Alavi I, Ghasemi E, Rabiei-Faradonbeh M. One-year prevalence of antimicrobial susceptibility pattern of methicillin-resistant Staphylococcus aureus recovered from raw meat. Trop Biomed. 2017;34:396-404.

50. Madahi H, Rostami F, Rahimi E, Dehkordi FS. Prevalence of enterotoxigenic Staphylococcus aureus isolated from chicken nugget in Iran. Jundishapur J Microbiol. 2014;7.

51. Bishop HG, Onyowoicho G. Escherichia coli and Staphylococcus aureus contaminations of carrots sold within Zaria, Nigeria and their antibiotic susceptibility profiles. Open Access J Sci. 2017;1:110-3.

52. Ma Y, Zhao Y, Tang J, Tang C, Chen J, Liu J. Antimicrobial susceptibility and presence of resistance \& enterotoxins/enterotoxin-likes genes in Staphylococcus aureus from food. CyTA J Food. 2018;16:76-84.

53. Waters AE, Contente-Cuomo T, Buchhagen J, Liu CM, Watson L, Pearce K, Foster JT, Bowers J, Driebe EM, Engelthaler DM. Multidrug-resistant Staphylococcus aureus in US meat and poultry. Clin Infect Dis. 2011;52:1227-30.

54. Dehkordi FS, Gandomi H, Basti AA, Misaghi A, Rahimi E. Phenotypic and genotypic characterization of antibiotic resistance of methicillin-resistant Staphylococcus aureus isolated from hospital food. Antimicrob Resist Infect Control. 2017;6:104.

55. Rahi A, Kazemeini H, Jafariaskari S, Seif A, Hosseini S, Dehkordi FS. Genotypic and Phenotypic-Based Assessment of Antibiotic Resistance and Profile of Staphylococcal Cassette Chromosome mec in the Methicillin-Resistant Staphylococcus aureus Recovered from Raw Milk. Infect Drug Resist. 2020;13:273.

56. Ngemenya MN, Djeukem GGR, Nyongbela KD, Bate PNN, Babiaka SB, Monya E, Kanso RK. Microbial, phytochemical, toxicity analyses and antibacterial activity against multidrug resistant bacteria of some traditional remedies sold in Buea Southwest Cameroon. BMC Complement Alternative Med. 2019;19:150.

57. Alfouzan W, Udo EE, Modhaffer A. Molecular Characterization of Methicillin-Resistant Staphylococcus aureus in a Tertiary Care hospital in Kuwait. Scientific Reports. 2019;9:1-8.

58. Mohammed J, Ziwa MH, Hounmanou YMG, Kisanga A, Tuntufye HN. Molecular typing and antimicrobial susceptibility of methicillin-resistant Staphylococcus aureus isolated from bovine milk in Tanzania. Int J Microbiol. 2018;2018.

59. Zhang L, Gao J, Barkema HW, Ali T, Liu G, Deng Y, Naushad S, Kastelic JP, Han B. Virulence gene profiles: alpha-hemolysin and clonal diversity in Staphylococcus aureus isolates from bovine clinical mastitis in China. BMC Vet Res. 2018;14:1-12.

60. Dallal MMS, Khoramizadeh MR, Amiri SA, Yaraghi AAS, Fard RMN. Coagulase gene polymorphism of Staphylococcus aureus isolates: A study on dairy food products and other foods in Tehran, Iran. Food Sci Human Wellness. 2016;5:186-90.

61. Gao M, Sang R, Wang G, Xu Y. Association of pvl gene with incomplete hemolytic phenotype in clinical Staphylococcus aureus. Infect Drug Resist. 2019;12:1649-56.

62. Elsayed MS, El-Bagoury AEM, Dawoud MA. Phenotypic and genotypic detection of virulence factors of Staphylococcus aureus isolated from clinical and subclinical mastitis in cattle and water buffaloes from different farms of Sadat City in Egypt. Vet World. 2015;8:1051-8.

63. Aung MS, Zi H, Nwe KM, Maw WW, Aung MT, Min W, Nyein N, Kawaguchiya M, Urushibara N, Sumi A. Drug resistance and genetic characteristics of clinical isolates of staphylococci in Myanmar: high prevalence of PVL among methicillin-susceptible Staphylococcus aureus belonging to various sequence types. New Microb New Infect. 2016;10:58-65.

64. Tahbaz SV, Fallah F, Nowroozi J, Armin S, Azimi L. Molecular Characterization of Exotoxin Genes in Staphylococcus aureus Recovered From Hospitalized Patients. J Med Bacteriol. 2019;8:21-9.

65. Rodrigues MX, Silva NCC, Trevilin JH, Cruzado MMB, Mui TS, Duarte FRS, Castillo CJC, Canniatti-Brazaca SG, Porto E. Molecular characterization and antibiotic resistance of Staphylococcus spp. isolated from cheese processing plants. J Dairy Sci. 2017;100:5167-75.

Page $14 / 19$ 
Figures

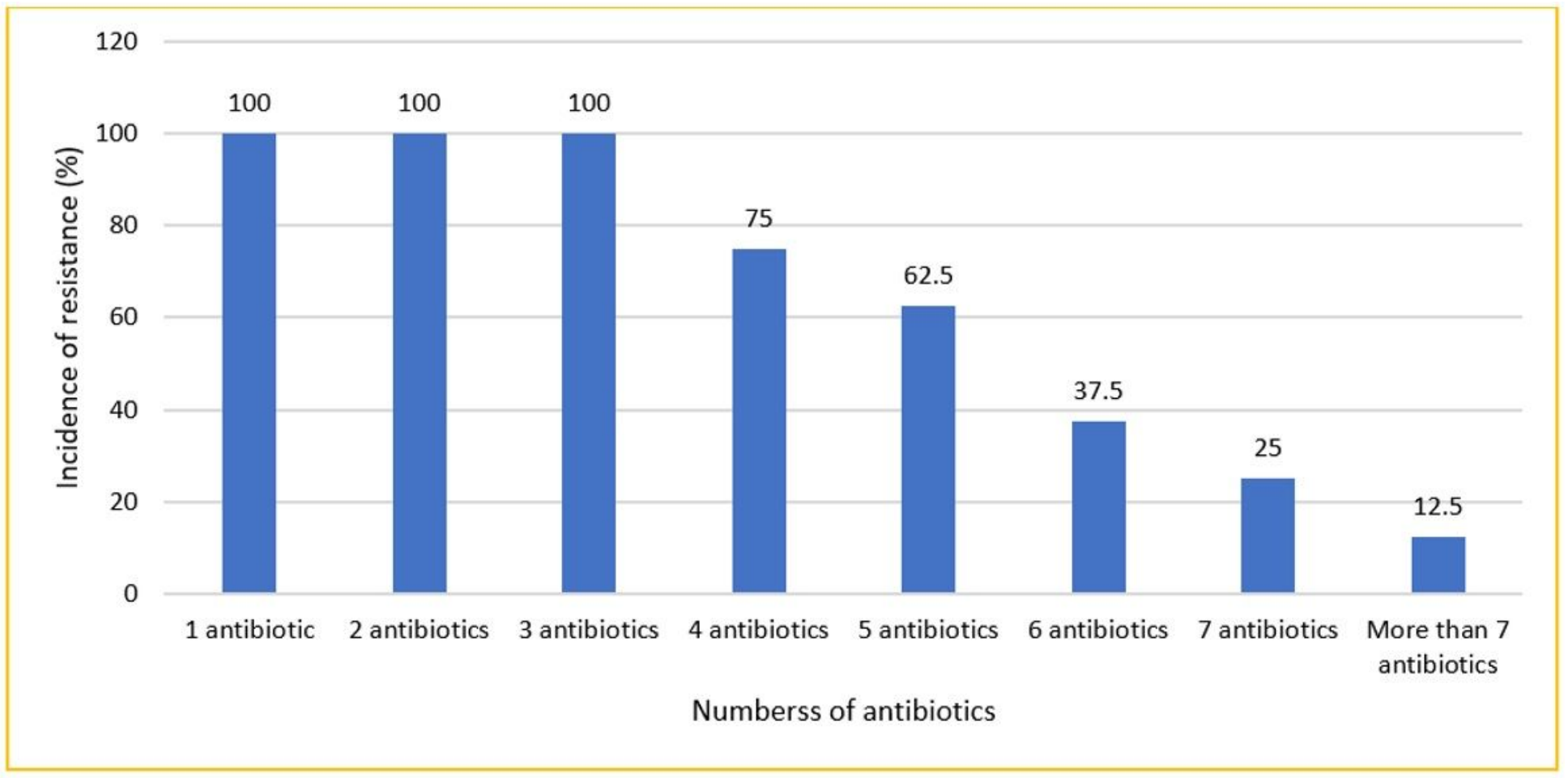

Figure 1

Prevalence of multidrug resistant-MRSA bacteria amongst vegetable samples.

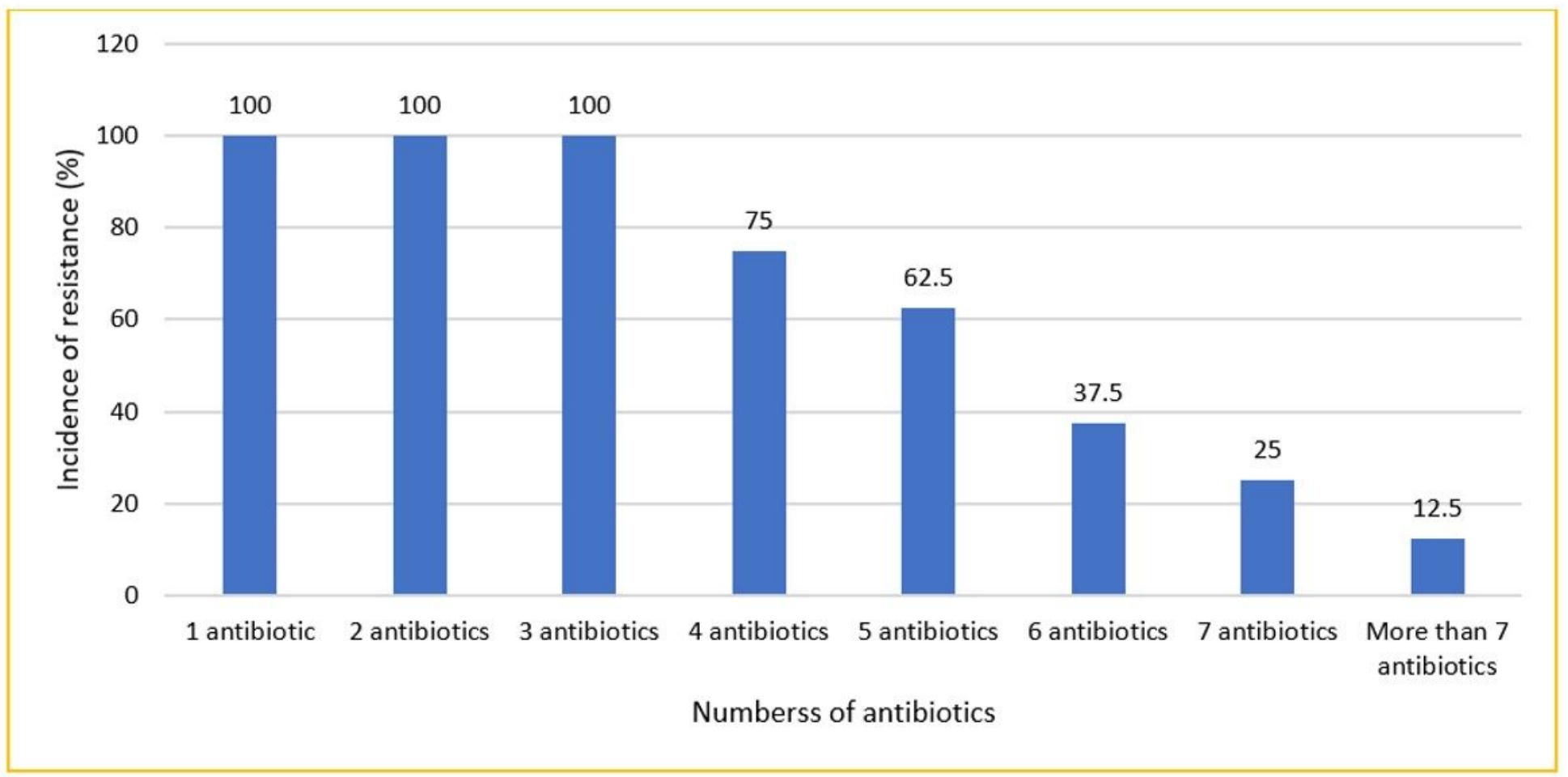

Figure 1

Prevalence of multidrug resistant-MRSA bacteria amongst vegetable samples. 


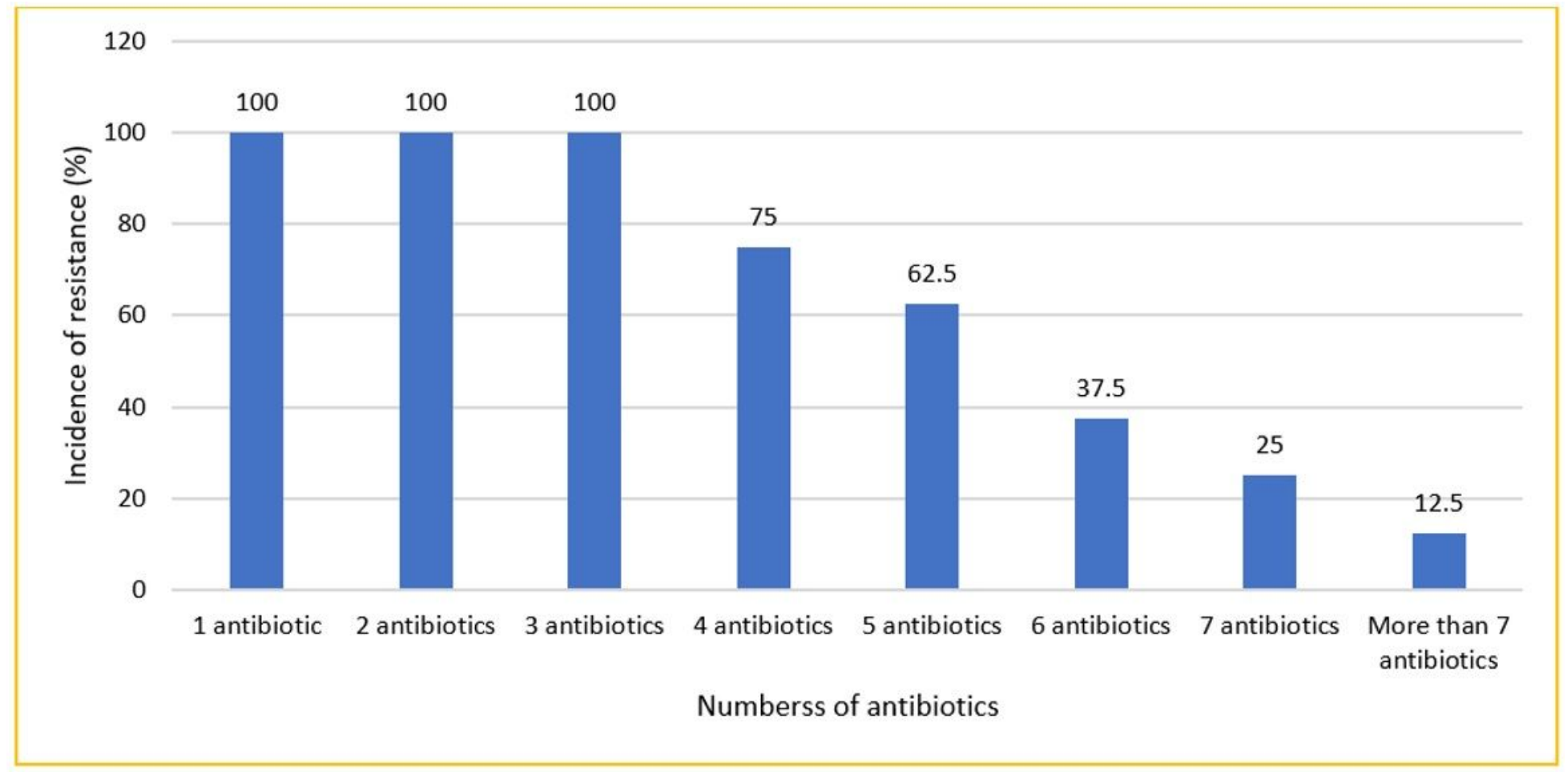

Figure 1

Prevalence of multidrug resistant-MRSA bacteria amongst vegetable samples.

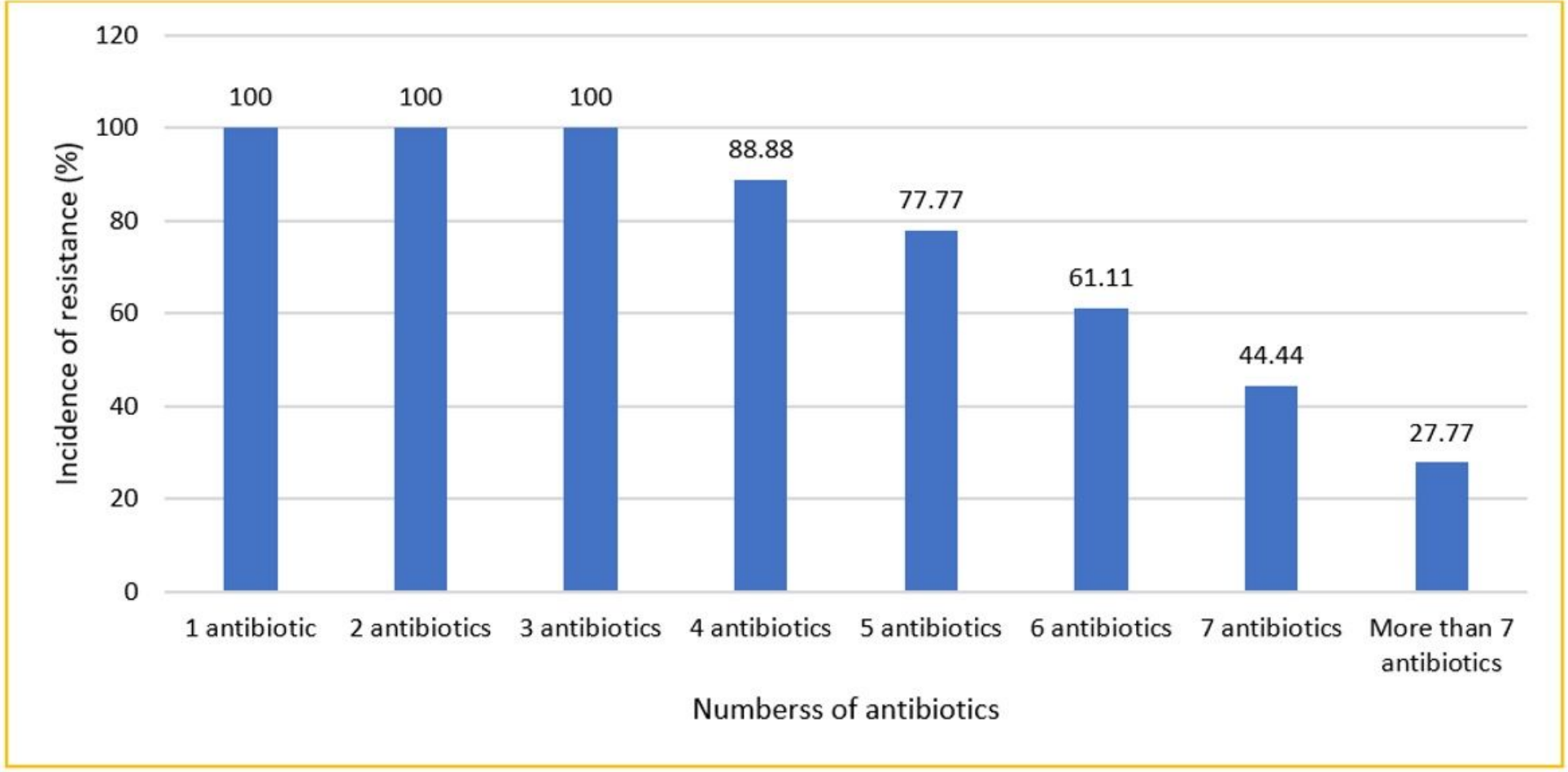

Figure 2

Prevalence of multidrug resistant-MRSA bacteria amongst salad samples. 


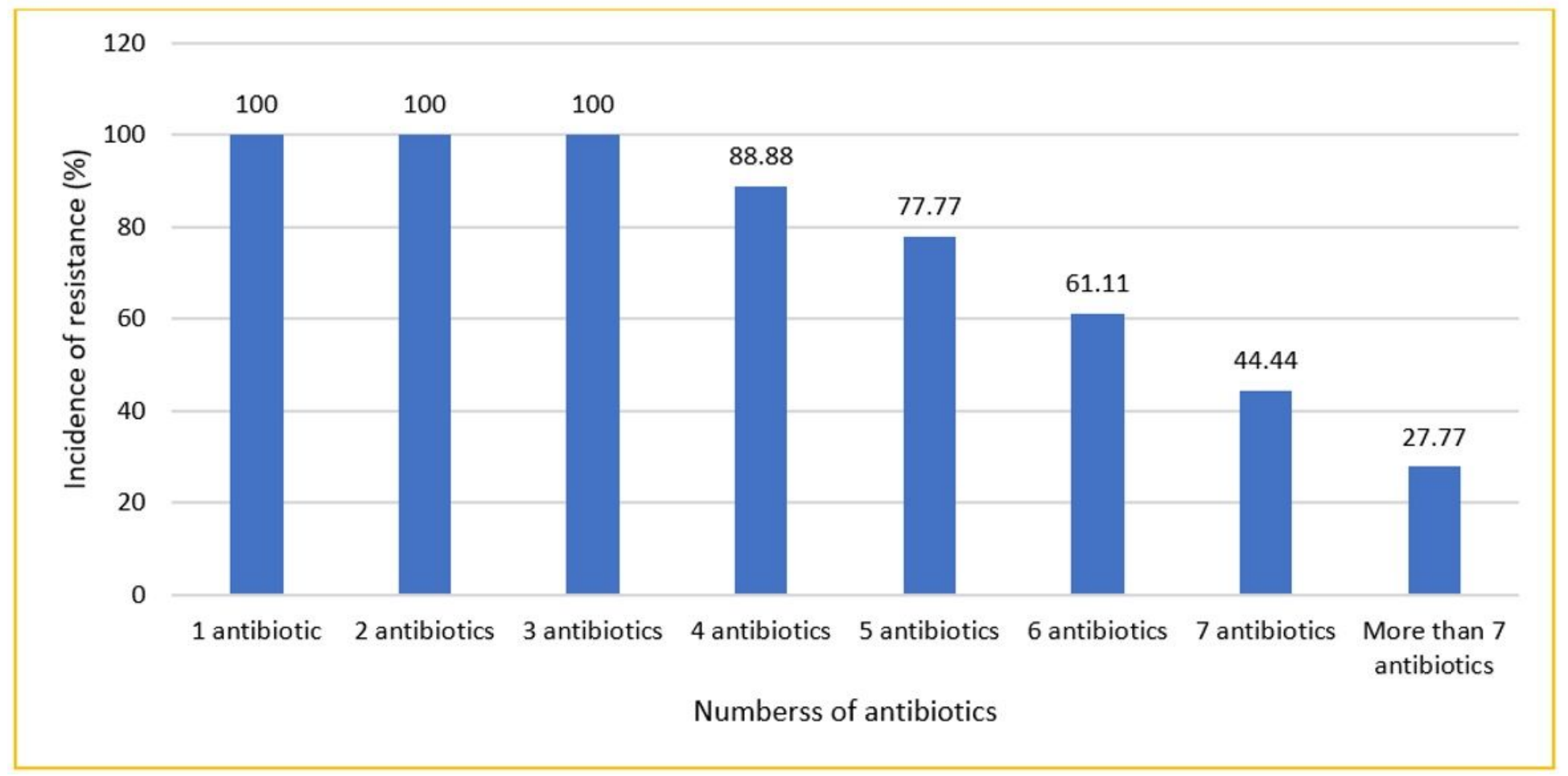

Figure 2

Prevalence of multidrug resistant-MRSA bacteria amongst salad samples.

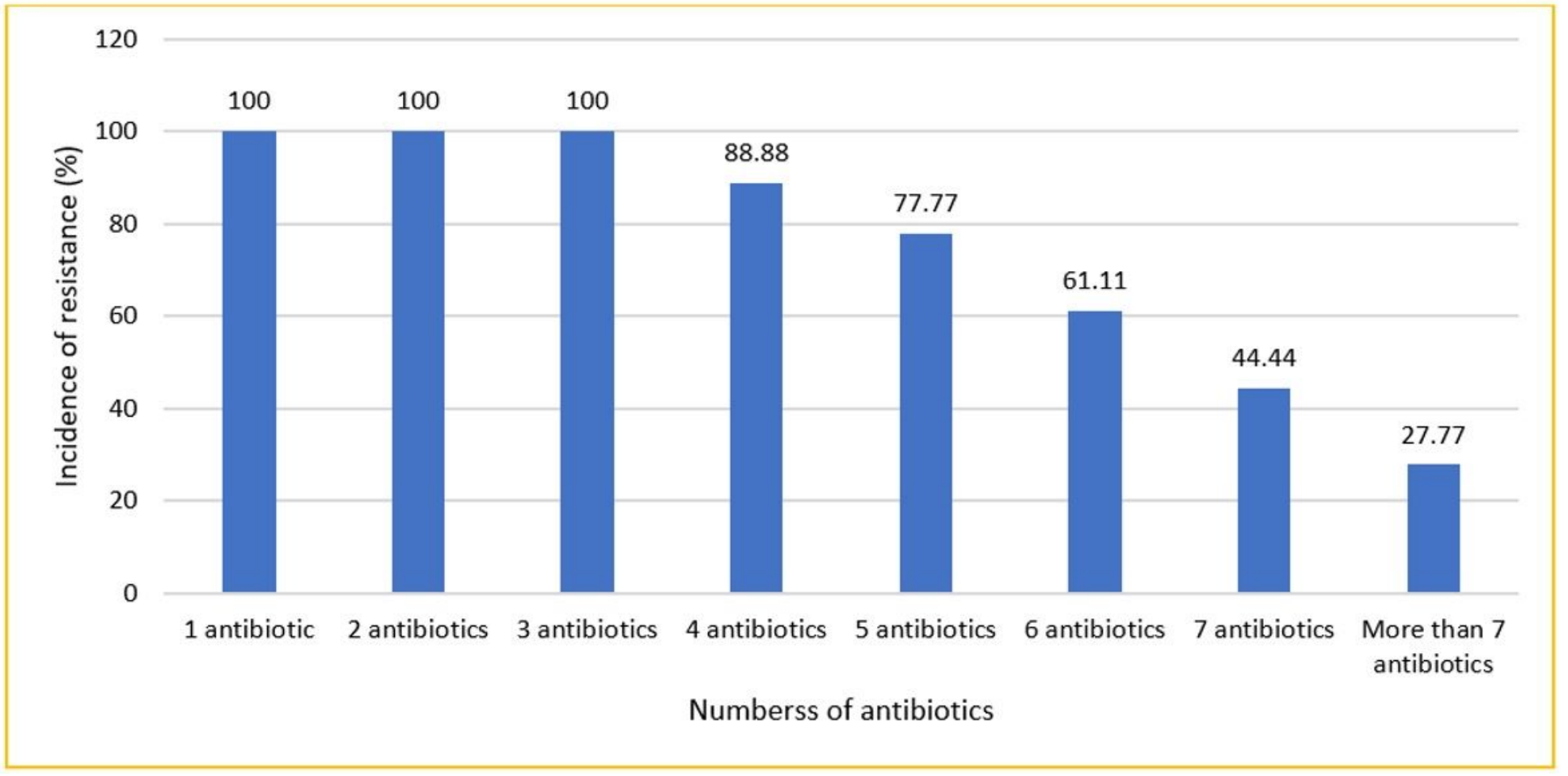

Figure 2

Prevalence of multidrug resistant-MRSA bacteria amongst salad samples. 
Tree Diagram (Jackard Coefficient)

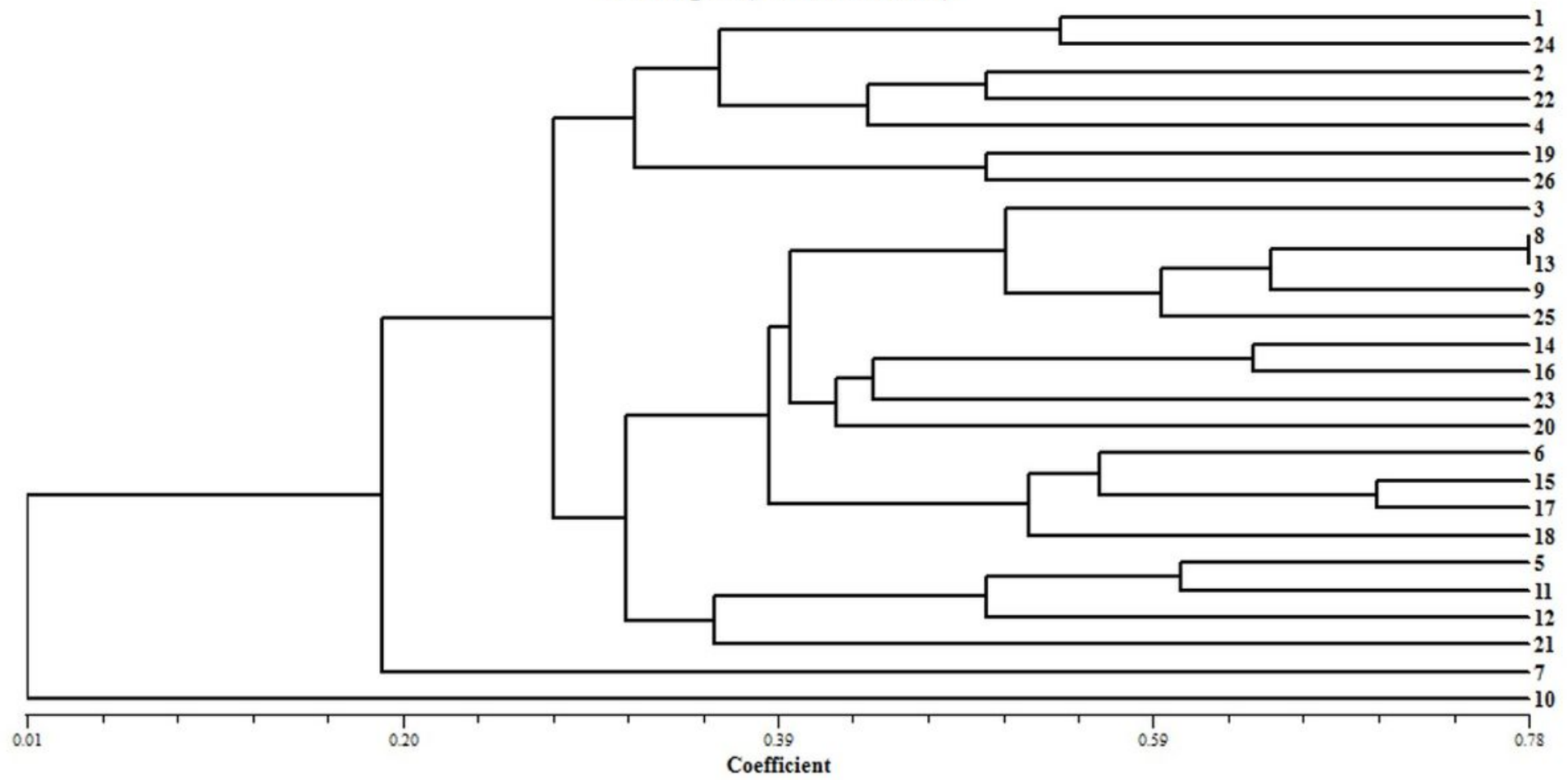

Figure 3

RAPD-PCR typing of MRSA strains isolated from vegetable and salad samples. All of the 26 MRSA isolates were considered.

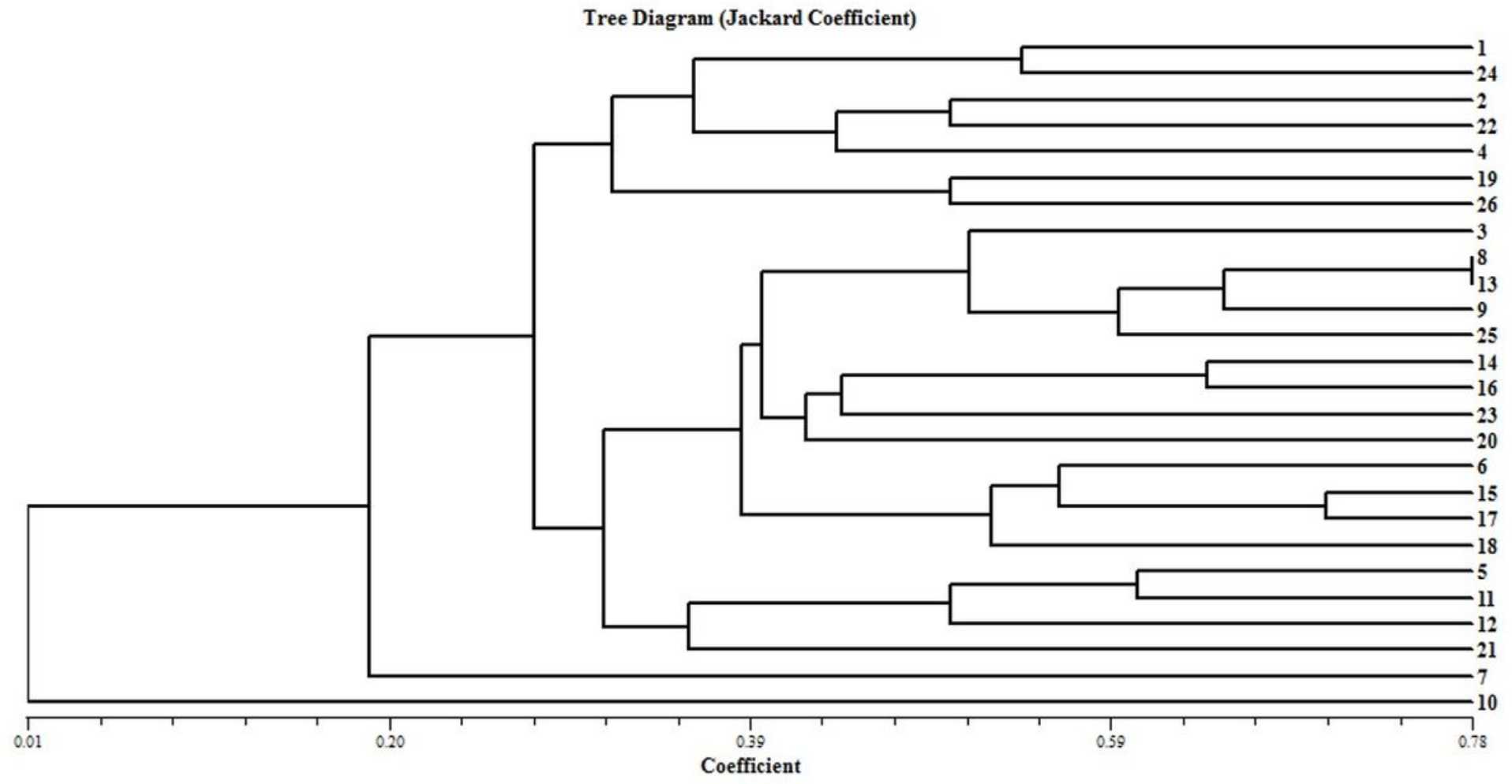

Figure 3

RAPD-PCR typing of MRSA strains isolated from vegetable and salad samples. All of the 26 MRSA isolates were considered. 
Tree Diagram (Jackard Coefficient)

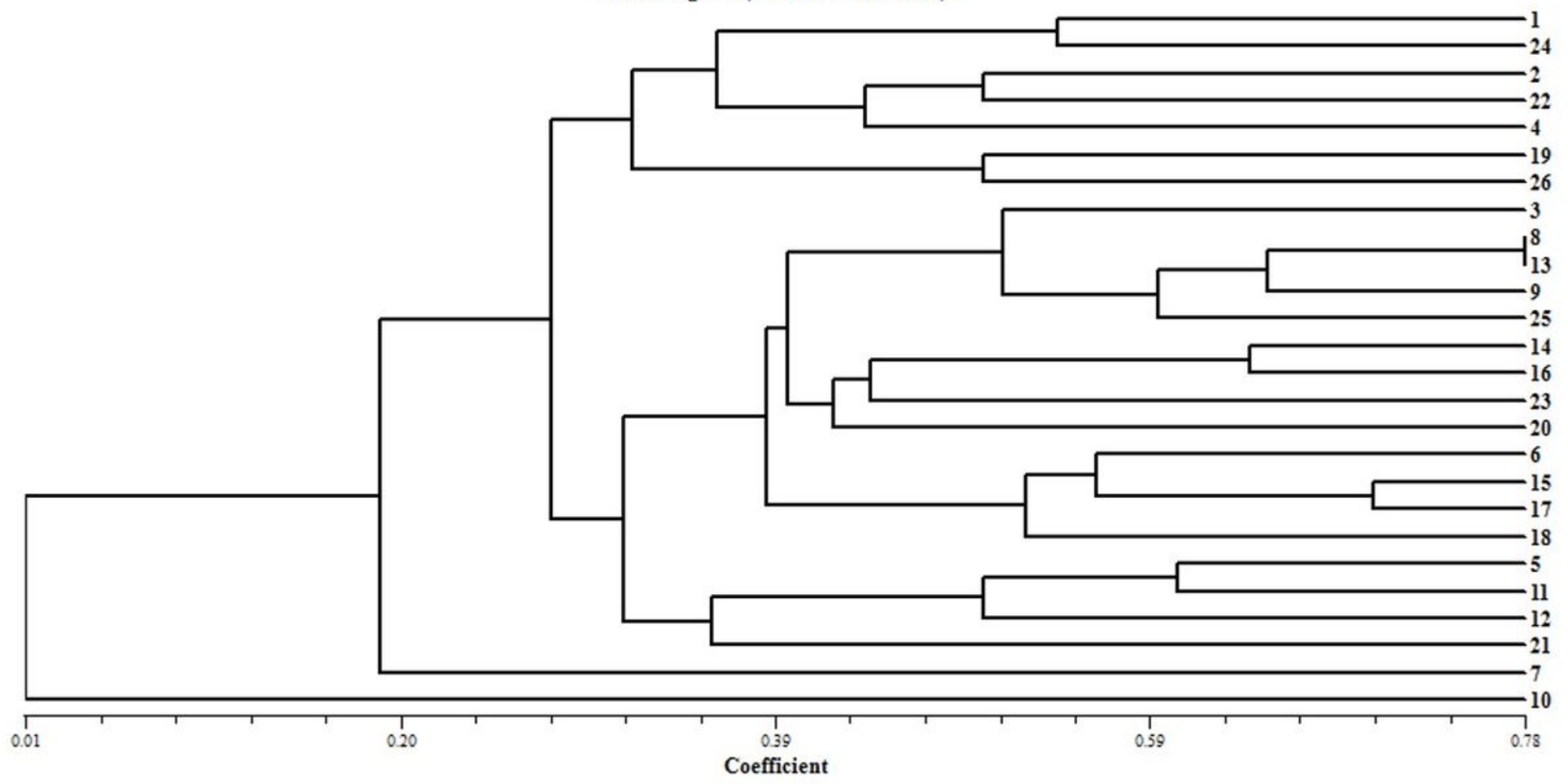

Figure 3

RAPD-PCR typing of MRSA strains isolated from vegetable and salad samples. All of the 26 MRSA isolates were considered. 